\title{
Guanine nucleotide exchange factor RABGEF1 regulates keratinocyte-intrinsic signaling to maintain skin homeostasis
}

\author{
Thomas Marichal, ${ }^{1,2,3}$ Nicolas Gaudenzio, ${ }^{1,3}$ Sophie El Abbas, ${ }^{2}$ Riccardo Sibilano, ${ }^{1,3}$ Oliwia Zurek, ${ }^{1,3}$ Philipp Starkl, ${ }^{1,3}$ \\ Laurent L. Reber, ${ }^{1,3}$ Dimitri Pirottin, ${ }^{2}$ Jinah Kim, ${ }^{1}$ Pierre Chambon, ${ }^{4}$ Axel Roers, ${ }^{5}$ Nadine Antoine, ${ }^{6}$ Yuko Kawakami, ${ }^{7,8}$ \\ Toshiaki Kawakami, ${ }^{7,8}$ Fabrice Bureau, ${ }^{2,9}$ See-Ying Tam, ${ }^{1,3}$ Mindy Tsai, ${ }^{1,3}$ and Stephen J. Galli, ${ }^{1,3,10}$ \\ 'Department of Pathology, Stanford University School of Medicine, Stanford, California, USA. ${ }^{2}$ Laboratory of Cellular and Molecular Immunology, GIGA-Research and Faculty of Veterinary Medicine, \\ University of Liège, Liège, Belgium. ${ }^{3}$ Sean N. Parker Center for Allergy and Asthma Research, Stanford University School of Medicine, Stanford, California, USA. ${ }^{4}$ Institut de Génétique et de Biologie \\ Moléculaire et Cellulaire, CNRS UMR7104/INSERM U964, Collège de France, Université de Strasbourg, Illkirch Cedex, France. ${ }^{5}$ Institute for Immunology, Medical Faculty Carl-Gustav Carus, \\ Technische Universität Dresden, Dresden, Germany. Department of Morphology and Pathology, Laboratory of Animal Histology, Faculty of Veterinary Medicine, University of Liège, Liège, Belgium. \\ ${ }^{7}$ Division of Cell Biology, La Jolla Institute for Allergy and Immunology, La Jolla, California, USA. ${ }^{8}$ Research Unit for Allergy, RIKEN Research Center for Allergy and Immunology, Yokohama, Japan. \\ ${ }^{9}$ Walloon Excellence in Lifesciences and Biotechnology (WELBIO), Wallonia, Belgium. ${ }^{10}$ Department of Microbiology and Immunology, Stanford University School of Medicine, Stanford, California, USA
}

\begin{abstract}
Epidermal keratinocytes form a structural and immune barrier that is essential for skin homeostasis. However, the mechanisms that regulate epidermal barrier function are incompletely understood. Here we have found that keratinocytespecific deletion of the gene encoding RAB guanine nucleotide exchange factor 1 (RABCEF1, also known as RABEX-5) severely impairs epidermal barrier function in mice and induces an allergic cutaneous and systemic phenotype. RABCEF1-deficient keratinocytes exhibited aberrant activation of the intrinsic IL-1R/MYD88/NF-KB signaling pathway and MYD88-dependent abnormalities in expression of structural proteins that contribute to skin barrier function. Moreover, ablation of MYD88 signaling in RABCEF1-deficient keratinocytes or deletion of I/1r1 restored skin homeostasis and prevented development of skin inflammation. We further demonstrated that epidermal RABCEF1 expression is reduced in skin lesions of humans diagnosed with either atopic dermatitis or allergic contact dermatitis as well as in an inducible mouse model of allergic dermatitis. Our findings reveal a key role for RABGEF1 in dampening keratinocyte-intrinsic MYD88 signaling and sustaining epidermal barrier function in mice, and suggest that dysregulation of RABCEF1 expression may contribute to epidermal barrier dysfunction in allergic skin disorders in mice and humans. Thus, RABCEF1-mediated regulation of IL-1R/MYD88 signaling might represent a potential therapeutic target.
\end{abstract}

\section{Introduction}

The mammalian epidermis forms a barrier to external insults, and homeostasis at cutaneous surfaces depends on tightly regulated interactions among the environment, epidermal keratinocytes, and host immune responses (1). Under homeostatic conditions, keratinocytes are continuously exposed to environmental stimuli but are able to maintain their structural integrity while coordinating appropriate immune responses implicated in tolerance and host defense $(1,2)$. Epidermal physical barrier function is mainly supported by structural proteins, including components of the stratum corneum and tight junctions (TJs) such as filaggrin $(1,3)$ and claudin $1(1,4,5)$, respectively. Keratinocytes also express a wide range of pattern recognition receptors and immune receptors $(2,6,7)$ that can sense danger signals and initiate innate

Authorship note: T. Marichal and N. Gaudenzio contributed equally to this work. S. El Abbas, R. Sibilano, O. Zurek, P. Starkl, and L.L. Reber contributed equally to this work. Conflict of interest: The authors have declared that no conflict of interest exists. Submitted: January 6, 2016; Accepted: September 29, 2016.

Reference information: J Clin Invest. 2016;126(12):4497-4515. doi:10.1172/JCI86359. immune responses by activating transcription factors such as $N F-\kappa B(2,8-10)$. In epithelial cells, balanced NF- $\kappa B$ signaling is essential for the maintenance of tissue homeostasis (11), and keratinocyte-intrinsic innate signaling pathways must be finely regulated to guard against pathogens while avoiding aberrant immune responses, including detrimental responses to allergens $(2,7,12)$.

Dysregulated epidermal barrier functions are increasingly thought to contribute to chronic allergic disorders of the skin, including atopic dermatitis (AD), which affects up to $10 \%-20 \%$ of children worldwide (1,13-15), and allergic contact dermatitis (ACD), a major occupational skin disease (16). Defects in filaggrin, including loss-of-function mutations of the $F L G$ gene $(3,17$, 18), represent a well-characterized predisposing factor for $\mathrm{AD}(3$, $19)$ and $\operatorname{ACD}(17,20)$. Keratinocyte activation and secretion of proinflammatory cytokines, such as thymic stromal lymphopoietin (TSLP) (21-23) or cytokines from the IL-1 family (24-26), also play a central role in the initiation and maintenance of aberrant immune responses associated with allergic skin disorders $(25,26)$. There is evidence that the aberrant barrier function and modified skin microenvironment observed in such settings endow dendritic cells 
A

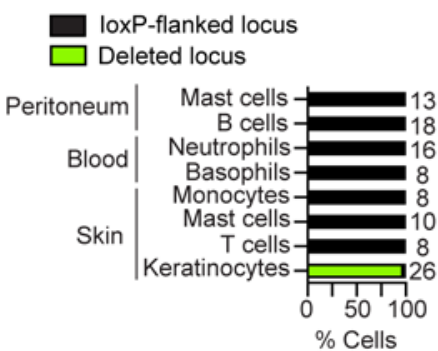

B

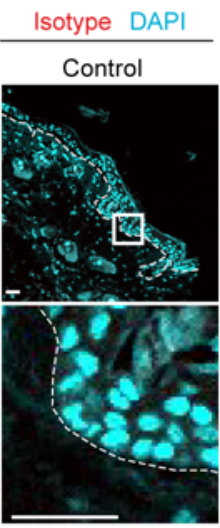

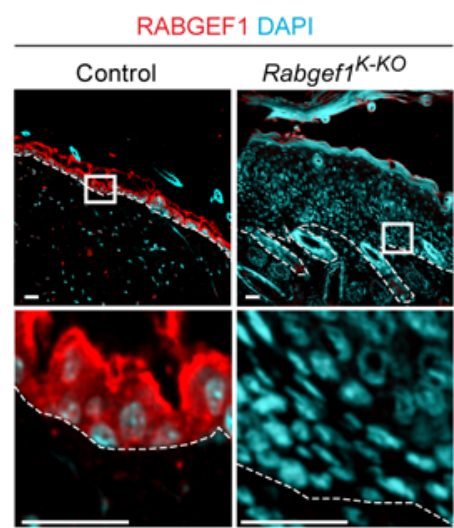
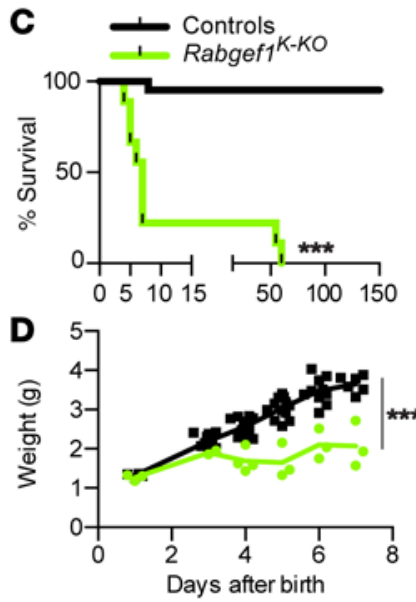

E

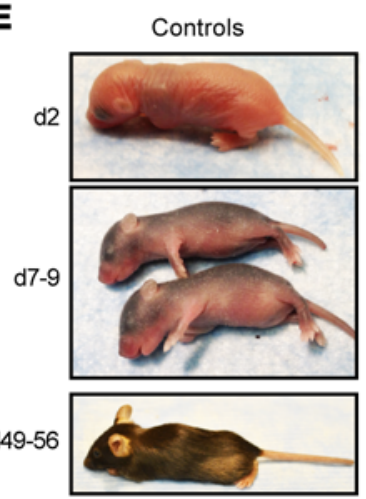

$\mathbf{F}$

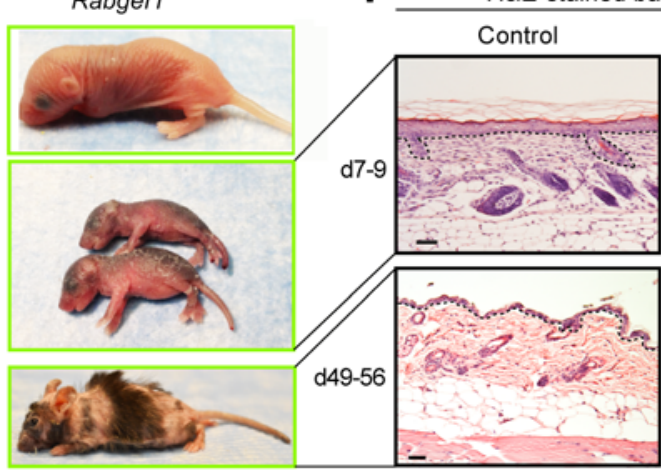

H\&E-stained back skin sections

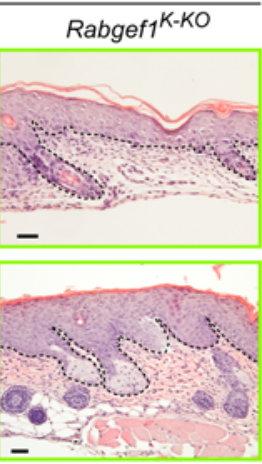

G

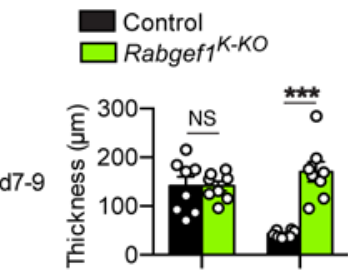

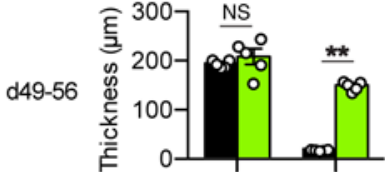

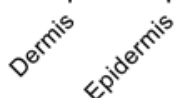

H

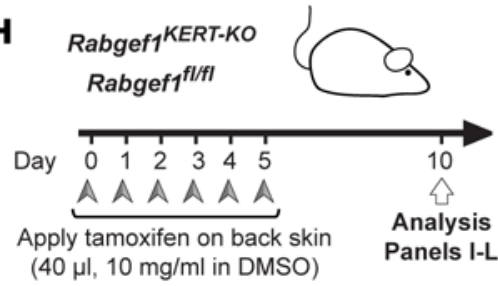

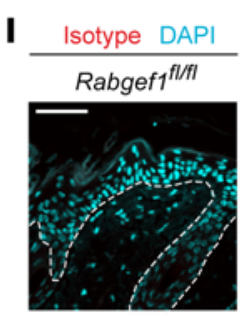

K

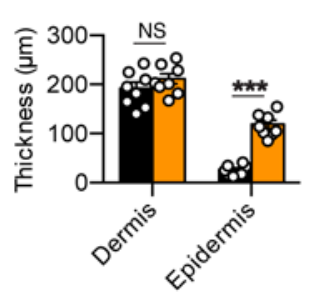

RABGEF1 DAPI

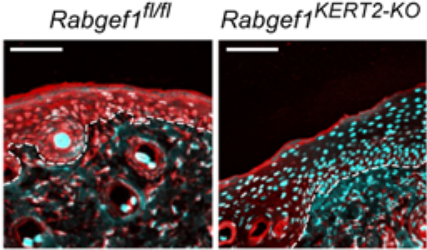

L

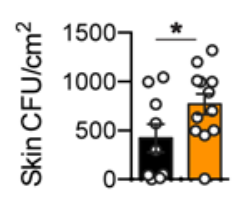

Tamoxifen - Rabgef $1^{f / / f}$

Tamoxifen - Rabgef1 1 KERT2-KO

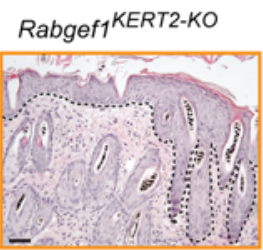


(DCs) with the capacity to induce a dominant type 2 cell-mediated immune response, characterized by cutaneous inflammation associated with the presence of eosinophils and $\mathrm{T}$ cells, activation of mast cells (MCs), and elevated blood levels of IgE (26-28). Yet the identification of intrinsic factors capable of modulating keratinocyte activation and influencing skin barrier functions is far from being complete, and a better understanding of these processes may lead to the development of improved strategies to support skin homeostasis and treat inflammatory disorders.

RAB guanine nucleotide exchange factor 1 (RABGEF1), also known as RABEX-5, is a multifunctional protein containing an A20-like zinc finger domain exhibiting E3 ubiquitin ligase activity (29) and a central Vps9 domain, which promotes GEF activity for the endocytic pathway regulator RAB5 (30). We characterized RABGEF1 as a negative regulator of MC activation in vitro (31-33); however, its physiological functions in vivo remain unknown. Here, we identify keratinocyte-intrinsic RABGEF1 as a critical regulator of skin homeostasis in mice and show that RABGEF1 can control the activation threshold of keratinocytes and limit IL-1R/MYD88-dependent signaling pathways, MYD88dependent barrier dysfunction, and skin inflammation. We also show that abnormalities in keratinocyte RABGEF1 expression can occur at sites of allergic skin inflammation in mice and humans, and may therefore contribute to the impairment of skin barrier function in such settings.

\section{Results}

Keratinocyte RABGEF1 expression is essential for health and prevents development of skin lesions. First, we sought to identify the RABGEF1-expressing cell type(s) critical for health, as mice that are globally deficient in RABGEF1 exhibit accelerated mortality and those surviving to adulthood develop skin inflammation (31, 34). We generated C57BL/6 Rabgef1 floxed mice (Rabgef $1^{f / f l}$ ) and crossed them with mice expressing Cre recombinase constitutively under the control of promoters specific for MCs (Mcpt5-Cre), myeloid cells (Lysz-Cre), or EpCAM ${ }^{+} \mathrm{CD} 45^{-}$epidermal keratinocytes (K14-Cre), as assessed by the use of $\mathrm{K}^{14-C r e} e^{+}$eYFP $\mathrm{Fl}^{f /+}$ mice (Supplemental Figure 1; supplemental material available online with this article; doi:10.1172/JCI86359DS1). The efficiency and specificity of Rabgef1 deletion were verified by single-cell PCR (Figure 1A and Supplemental Figure 2A). Complementary confocal microscopy staining showed that RABGEF1 protein was mainly expressed in keratinocytes of control mice, and efficiently and selectively deleted in keratinocytes of $\mathrm{K}^{14}-\mathrm{Cre}^{+} \mathrm{Rabgef1} \mathrm{fl}^{f / f l}$ (named Rabgef1 ${ }^{K-K O}$ ) mice (Figure 1B).

Mice with MC- or "myeloid"-restricted Rabgef1 deletion exhibited neither accelerated mortality nor obvious macroscopic abnormalities at least until the age of 12 months (Supplemental Figure 2, B and C). Mice with keratinocyte-intrinsic Rabgef1 deletion were born in the expected Mendelian proportion and were indistinguishable from control mice until postnatal day 2-3 (Figure 1, C-E). However, as early as postnatal day 7-9, Rabgef $1^{K-K O}$ mice exhibited accelerated mortality, weight loss, and skin lesions characterized by epidermal hyperplasia (Figure 1, C-G). The cause of accelerated mortality in Rabgef $1^{K-K O}$ mice is still unclear. We performed histological analysis of some of these mice that survived until day 49-56, when they were near death, focusing especially on those tissues that may exhibit some expression of keratin 14 (K14) in epithelial cells. However, these organs did not exhibit histological abnormalities (Supplemental Figure 3). These results indicate that the cause of death in such mice is more likely related to the skin abnormalities.

Because of the accelerated mortality in Rabgef $1^{K-K O}$ mice, and to assess the function of keratinocyte-intrinsic RABGEF1 in adult mice that would exhibit no potential developmental effects of constitutive Rabgef1 deletion, we generated mice in which Rabgef1 can be depleted in keratinocytes by tamoxifen treatment, i.e., K14-Cre-

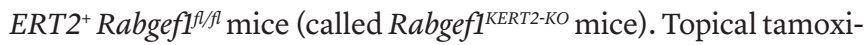

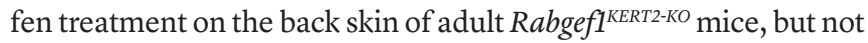
adult Rabgef $1^{f / f l}$ mice, promoted the development of skin lesions that were similar to those in Rabgef1 ${ }^{K-K O}$ mice and were associated with RABGEF1 deletion in keratinocytes (Figure 1, H-K). Such skin lesions were associated with a modest, albeit statistically significant, increase in the number of bacteria that could be cultured from the affected skin (Figure 1L), but not with evidence of associated systemic bacterial infection (Supplemental Figure 4).

$R A B G E F 1$ deletion in keratinocytes results in epidermal barrier dysfunction, features of type 2 skin inflammation, and elevated levels of IgE antibodies. Histological and immunohistological analyses of back skin from newborn mice did not reveal obvious differences between Rabgef1 $1^{K-K O}$ and control mice (Supplemental Figure 5). By contrast, back skin lesions of postnatal day 7-9 as well as day 49-56 (i.e., adult) Rabgef1 ${ }^{K-K O}$ mice exhibited marked epidermal hyperplasia (Figure 1, F and G) and spongiosis (Figure 2A). Immunostaining revealed that keratinocytes in Rabgef $1^{K-K O}$ mice exhibited aberrant expression of K14 (normally expressed in basal layers) in suprabasal keratinocytes, as well as decreased expression of K10 and loricrin (markers of differentiated keratinocytes) (Supplemental Figure 6). Consistent with their hyperplastic phenotype, RABGEF1-deficient keratinocytes also displayed increased staining for K6 (induced following physical, chemical, or inflammatory stress; ref. 35 ) and the proliferative marker Ki67, an observation that was confirmed at the mRNA level (Figure 2, B and C). RABGEF1 deficiency also altered the expression of epidermal proteins that sustain barrier function, as keratinocytes of Rabgef1 ${ }^{K-K O}$ mice exhibited decreased expression of claudin 1 (Figure 2, D and E) and aberrant expression of filaggrin (normally expressed most strongly in the stratum corneum) in the stratum granulosum (Figure 2, D and E).

These observations prompted us to investigate whether keratinocyte-intrinsic RABGEF1 deficiency resulted in epidermal barrier dysfunction. We used our model of inducible keratinocyte Rabgef1 deletion by topical tamoxifen treatment of Rabgef $1^{\text {KERT2-KO }}$ mice and assessed barrier function by measuring transepidermal water loss (TEWL) (ref. 36 and Figure 2F). As shown in Figure 2G, TEWL was significantly increased in the back skin of tamoxifen-treated

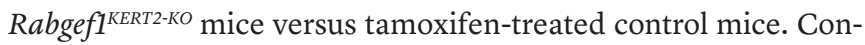
sistent with the increased permeability of the skin, the transepidermal passage of a harmless antigen, ovalbumin (OVA), patched on the skin was also potentiated when RABGEF1 was defective in keratinocytes. Indeed, dermal DC uptake and endosomal digestion of OVA was also substantially induced in tamoxifen-treated

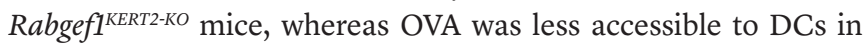
vehicle-treated Rabgef1 ${ }^{\text {KERT2-KO }}$ mice or tamoxifen-treated littermate control mice (Figure $2 \mathrm{H}$ ). 
A

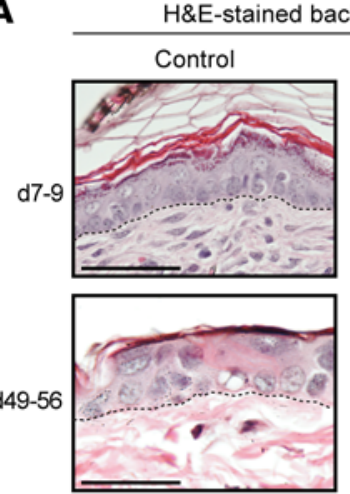

C
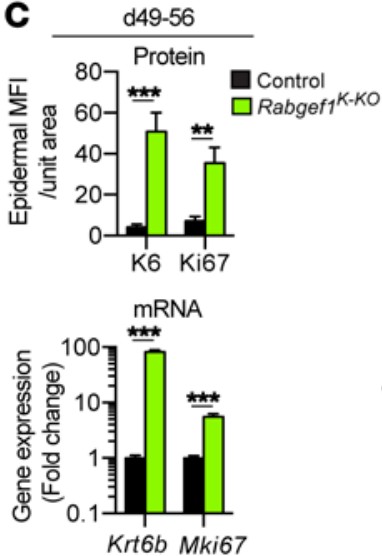

$\mathbf{F}$

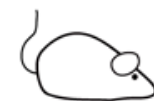

Rabgef1 KERT-KO Rabgeff $f^{f|f|}$

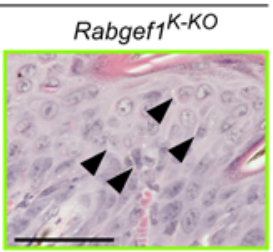

B
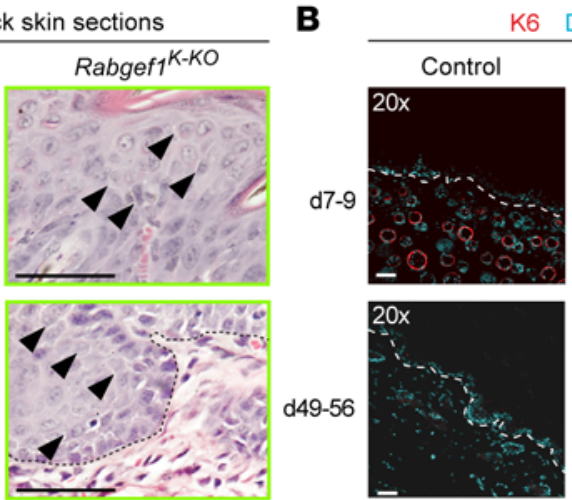

DAPI
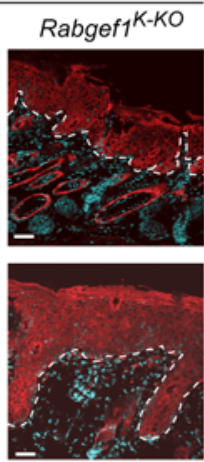
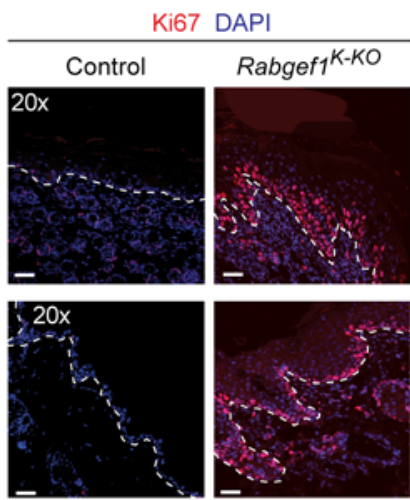

D
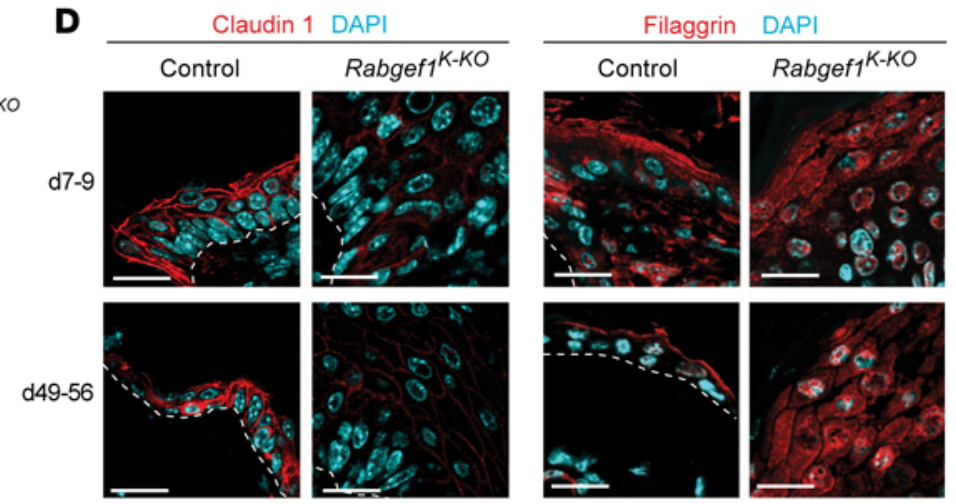

E
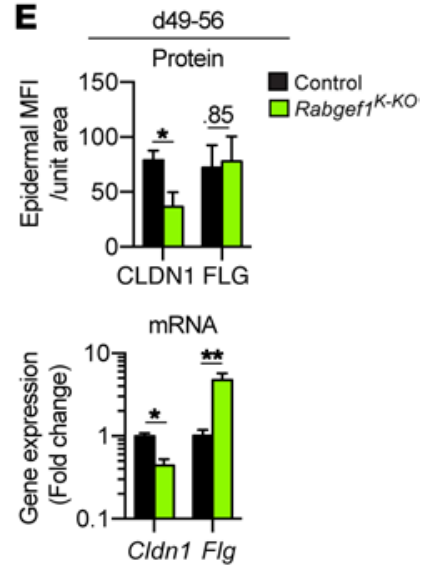

H

Back skin Live CD $45^{+}$cells

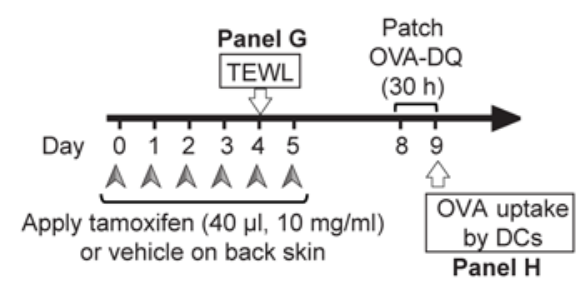

G
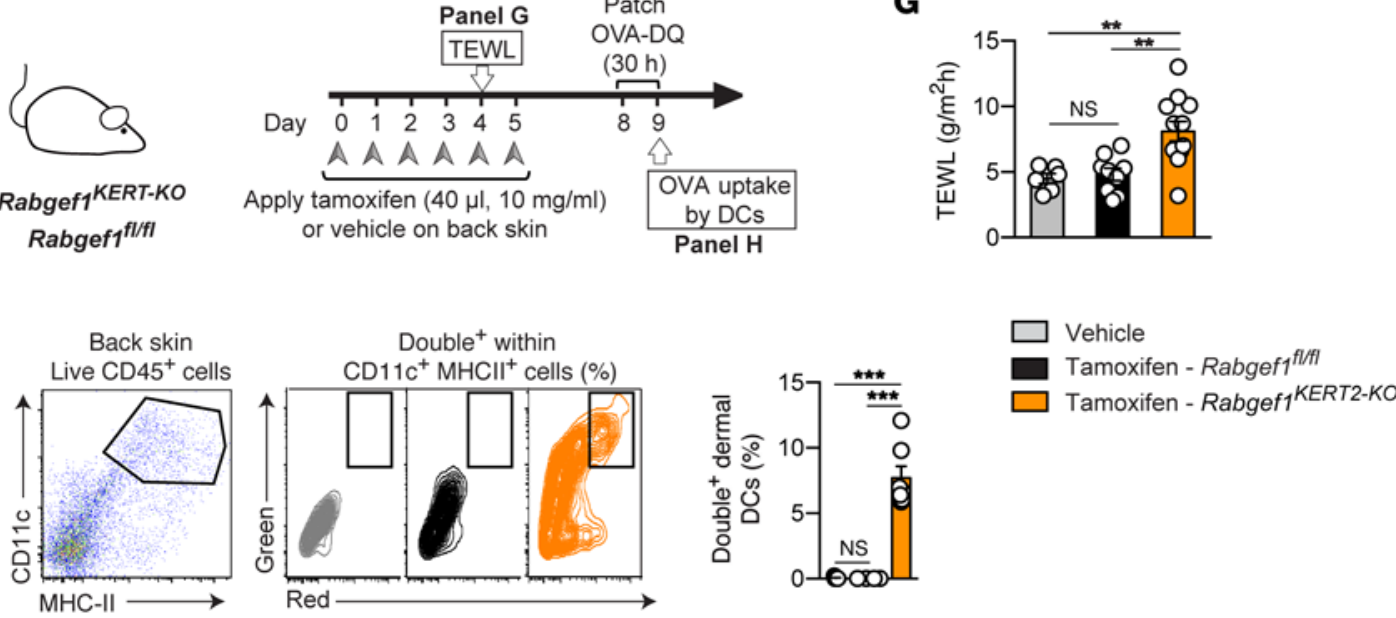

Figure 2. Epidermal abnormalities and barrier dysfunction in mice with deletion of RABGEF1 in keratinocytes. (A-E) Comparison of Rabgef $7^{-K O}$ and control mice. (A) Representative H\&E staining of back skin sections. Arrowheads indicate spongiosis. (B and $\mathbf{D})$ Representative confocal microscopy pictures of back skin sections with the indicated staining. ( $\mathbf{C}$ and $\mathbf{E}$ ) Bars show protein and mRNA levels of the indicated molecules whose staining is depicted in $\mathbf{B}$ and $\mathbf{D}$, as assessed by confocal microscopy and RT-qPCR analyses, respectively ( $n=4-6$ mice per group). (F) Experimental outline for assessment of epidermal barrier function in tamoxifen-treated Rabgef $1^{K E R T 2-K O}$ mice. (C) TEWL measurements; results are pooled from 2 independent experiments ( $n=6-12$ per group). (H) Percentage of dermal DCs containing processed OVA (as assessed by fluorescence in green and red) 30 hours after OVA-DQ skin patching; results are pooled from 3 independent experiments ( $n=6-8$ per group). (A, B, and $\mathbf{D})$ Pictures are representative of 4 or 5 samples (from $4-5$ different mice) per group, each giving similar results. (C, E, $\mathbf{G}$, and $\mathbf{H})$ Results are shown as mean $\pm \mathrm{SEM}$, and $\mathbf{G}$ and $\mathbf{H}$ also show individual values. (A, B, and $\mathbf{D})$ Dashed lines identify the dermal-epidermal junction. $P$ values were calculated by 2-tailed unpaired Student's $t$ test $(\mathbf{C}$ and $\mathbf{E})$ and 1-way ANOVA followed by Tukey's multiple comparison tests $(\mathbf{G}$ and $\mathbf{H}){ }^{*} P<0.05$; ${ }^{* *} P<0.01$; ${ }^{* * *} P<0.001$. Scale bars: $50 \mu \mathrm{m}$; original magnification, $\times 20$ (B) or $\times 63$ (D); TEWL, transepidermal water loss; NS, not significant.

Such epidermal barrier dysfunction in Rabgefi $1^{K-K O}$ mice was associated with a dominant type 2 cutaneous inflammatory response as well as systemic immune abnormalities. First, back skin from Rabgef $1^{K-K O}$ mice exhibited enhanced expression of the keratinocyte-associated type 2 cytokine TSLP (refs. 21, 22, and Figure 3A), increased numbers of dermal MCs (Figure 3B), and dermal infiltration of leukocytes, including T cells, eosinophils, and neutrophils (Figure 3, C and D). Second, adult Rabgef ${ }^{\text {K-KO }}$ mice 
A
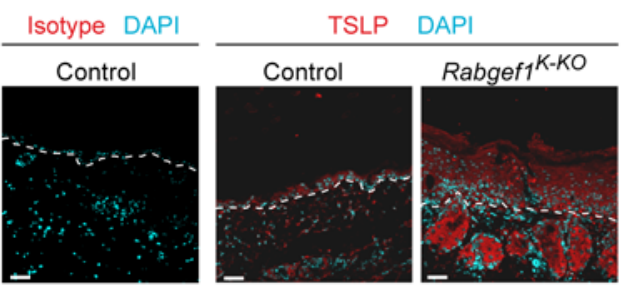

C
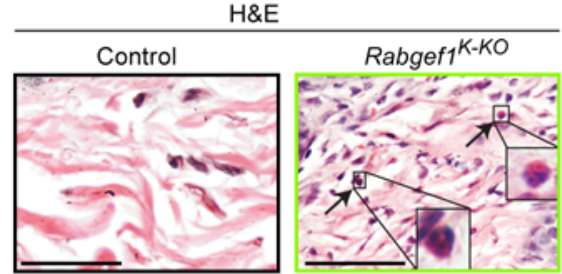

Control $\square$ Rabgef1 ${ }^{K-K O}$

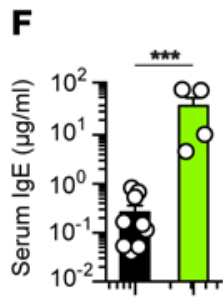

G

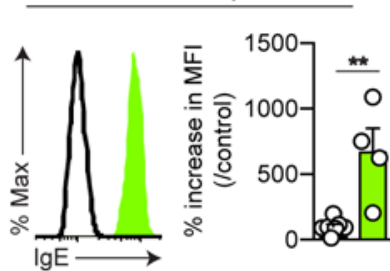

H

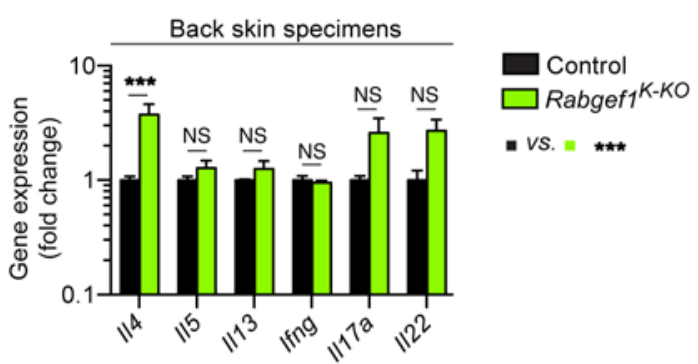

B

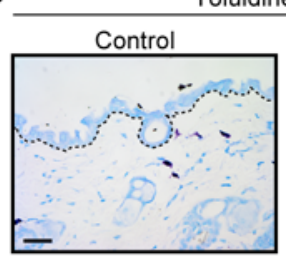

D Live dermal cells

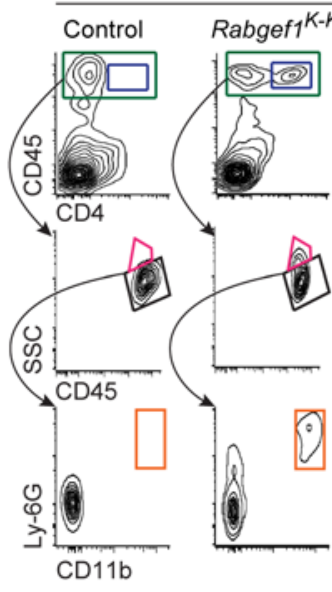

I

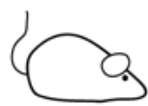

Rabgef1 ${ }^{\text {KERT-KO }}$ Rabgef1 $1^{f \mid f l}$
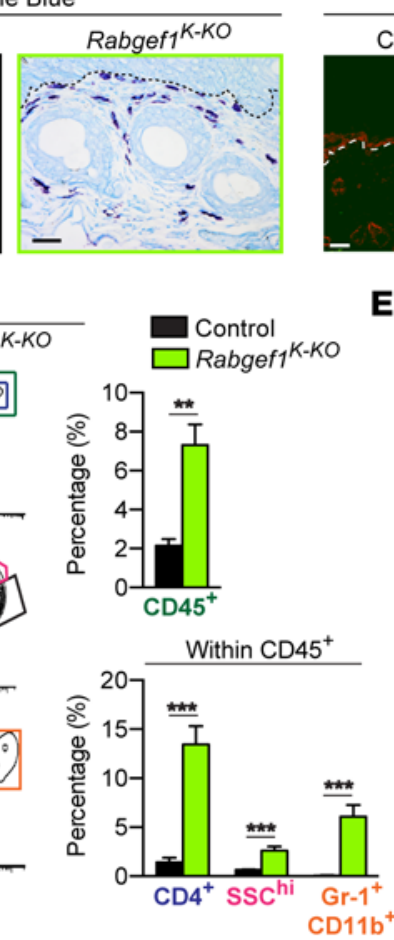

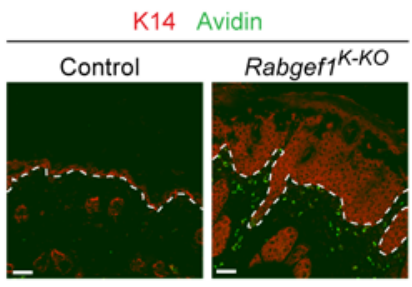

E Skin-draining lymph nodes

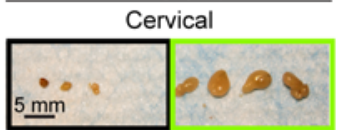

Inguinal
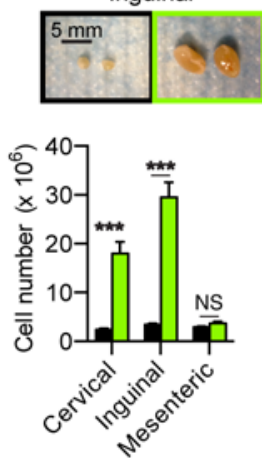

$\mathrm{CD}^{+} \mathrm{T}$ cell

phenotyping

Dermis / LN

Day $\begin{array}{llllllllllll}0 & 1 & 2 & 3 & 4 & 5 & 6 & 7 & 8 & 9 & 10\end{array}$

$\wedge \wedge \wedge \wedge \wedge \wedge$

Apply tamoxifen on ear pinnae

$(20 \mu \mathrm{l}, 10 \mathrm{mg} / \mathrm{ml}$ in corn oil)

J

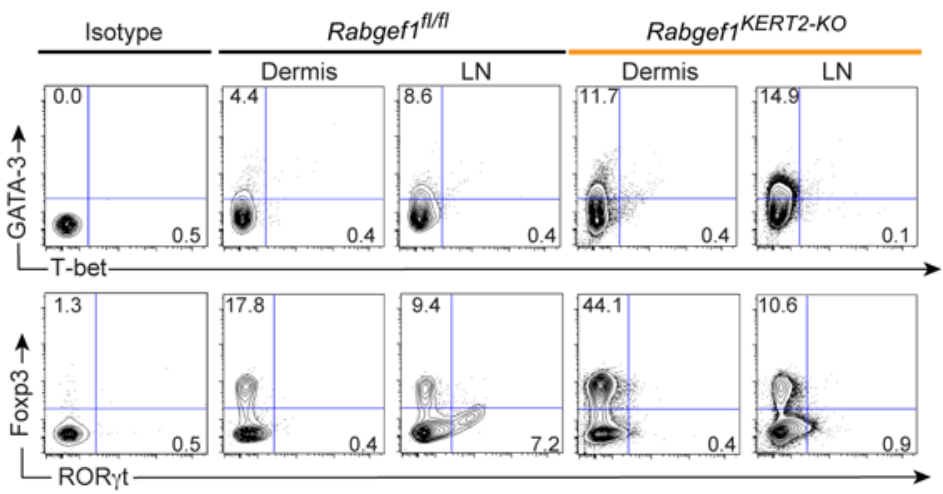

K
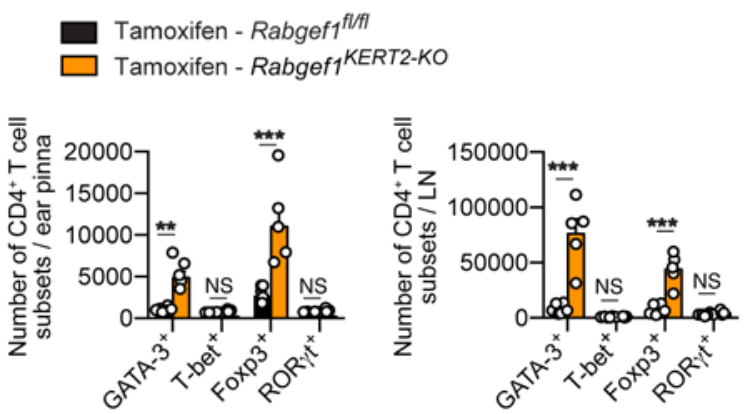

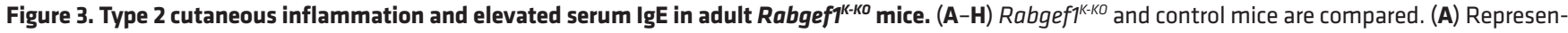
tative TSLP staining of back skin sections. (B) Assessment of dermal MCs by toluidine blue (left panel) or avidin staining (right panel) (82). (C) Representative H\&E staining of back skin sections (different areas of the sections in Figure 2A); arrows indicate eosinophils. (D) Representative dot plot of dermal CD45+ leukocytes, CD4+ T cells, SSChi eosinophils (also positive for SiglecF), and Ly6G(Gr-1)+CD11b+ neutrophils; bar graphs show quantification of the percentage of cells ( $n=6-8$ per group). (E) Representative pictures of skin-draining lymph nodes (DLNs); bar graphs show quantification of $L N$ cell numbers ( $n=8-20$ mice per group). ( $\mathbf{F}$ and $\mathbf{G}$ ) Assessment of IgE levels in the serum ( $n=4-10$ mice per group) (F) and on the surface of blood basophils (G); bar graph in $\mathbf{G}$ shows quantification of the percentage increase in mean fluorescence intensity (MFI) versus control mice ( $n=4-10$ per group). (H) RT-qPCR analysis of the selected genes ( $n=3$ mice per group). (I) Experimental outline. (J) Representative dot plots depicting intracellular protein expression of GATA-3, T-bet, Foxp3, and ROR- $\gamma \mathrm{t}$ within living $C D 4^{+} T$ cells. Insets show percentage of cells in the gated subpopulation. (K) Bars show quantification of the numbers of CD4 ${ }^{+} T$ cell subsets in the dermis of the ear pinnae (left) and in the DLN (right) ( $n=5-6$ mice per group, 2 independent experiments). (A-C) Pictures are representative of 4 or 5 samples per group, each giving similar results. (D-H and $\mathbf{K}$ ) Results are shown as mean \pm SEM, and $\mathbf{F}, \mathbf{G}$, and $\mathbf{K}$ also show individual values. (A-C) Dashed lines identify the dermal-epidermal junction. $P$ values were calculated by 2-tailed unpaired Student's $t$ test (E-G) and 2-way ANOVA followed by Bonferroni's test for multiple comparisons ( $\mathbf{H}$ and $\mathbf{K}$ ). ${ }^{* *} P<0.01 ;{ }^{* *} P<0.001$. Scale bars: $50 \mu \mathrm{m}$; original magnification in $\mathbf{A}$ and $\mathbf{B}, \times 20$; NS, not significant. 
A Differentially expressed genes $(P<0.01, \mathrm{FC}>2)$
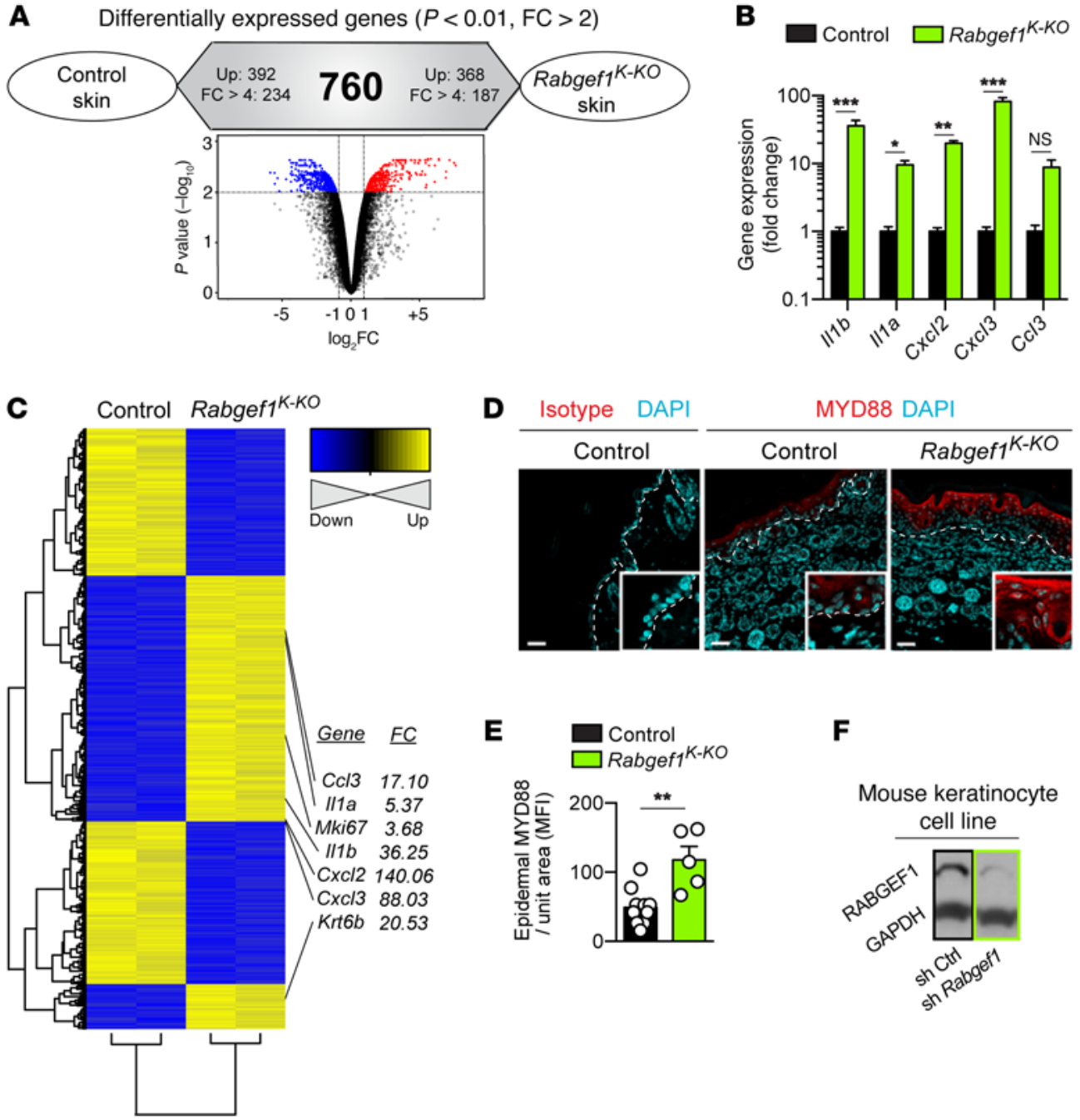

D Isotype DAPI

MYD88 DAPI

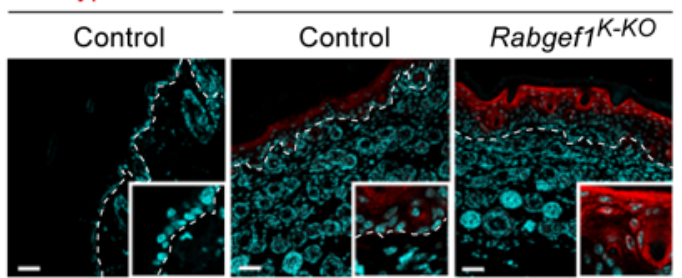

E

F

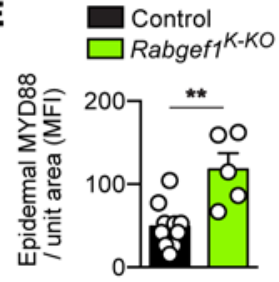

Mouse keratinocyte cell line

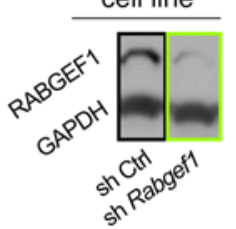

G

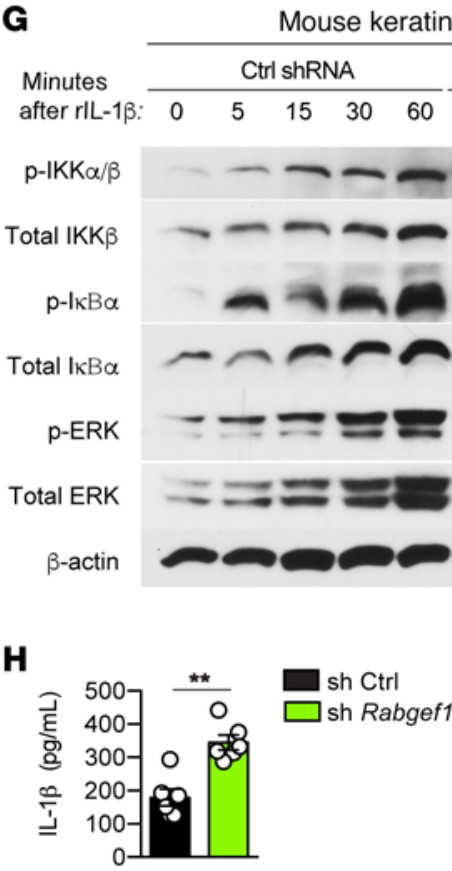

Figure 4. Increased activation of the IL-1R/MYD88/NF-KB pathway in RABGEF1-deficient keratinocytes.

(A) Differentially expressed (DE) genes between adult Rabgef $7^{K-K O}$ and control mouse back skin specimens ( $n=2$ analyses per group) showing $\mathrm{DE}$ genes in red/blue. Volcano plot: 760 = total number of DE genes; direction of differential expression is indicated for all DE and highly DE (fold change [FC] >4) genes. (B) RTqPCR analysis of the selected genes ( $n=4$ mice per group). (C) Expression of DE genes between back skin specimens from adult Rabgef $7^{\text {K-Ko }}$ and control mice, indicating (on right) names and $F C$ of DE genes whose transcript expression was confirmed by RT-qPCR. (D) MYD88 staining of back skin sections from adult mice. Dashed lines: dermal-epidermal junction. (E) Bar graphs show quantification of epidermal MYD88 levels ( $n=5-10$ mice per group). (F-H) Mouse PDV keratinocyte cells were transfected with control (Ctrl) shRNA or shRNA against Rabgef1 (Rabgef1 shRNA). (F) Western blot showing RABCEF1 and CAPDH (control) expression following shRNA transfection. The sh Ctrl and sh Rabgef1 lanes were run on the same gel but were noncontiguous. (G) Levels of the indicated phospho-proteins and total proteins at different times following recombinant IL-1 $\beta$ ( $r$ IL-1 $\beta$ ) stimulation (results representative of 1 of 2 independent experiments performed with 2 separate batches of cells). (H) Baseline IL-1 $\beta$ secretion of RABGEF1-deficient keratinocytes in vitro as assessed by ELISA ( $n=6$ per group, 2 independent experiments performed with 2 different batches of cells). (B, E, and $\mathbf{H}$ ) Data are mean \pm SEM; $\mathbf{E}$ and $\mathbf{H}$ also show individual values. $P$ values were calculated using a 2-way ANOVA test followed by Sidak's multiple comparison test (C) and a 2-tailed Student's $t$ test $(\mathbf{E}$ and $\mathbf{H}) .{ }^{*} P<0.05$; ${ }^{* *} P<0.01$; ${ }^{* *} P<0.001$. Scale bars: $50 \mu \mathrm{m}$; original magnification in $\mathbf{D}$ $\times 20$; NS, not significant. 
GSEA analysis between Rabgef1 ${ }^{K-K O}$ skin and defined gene sets

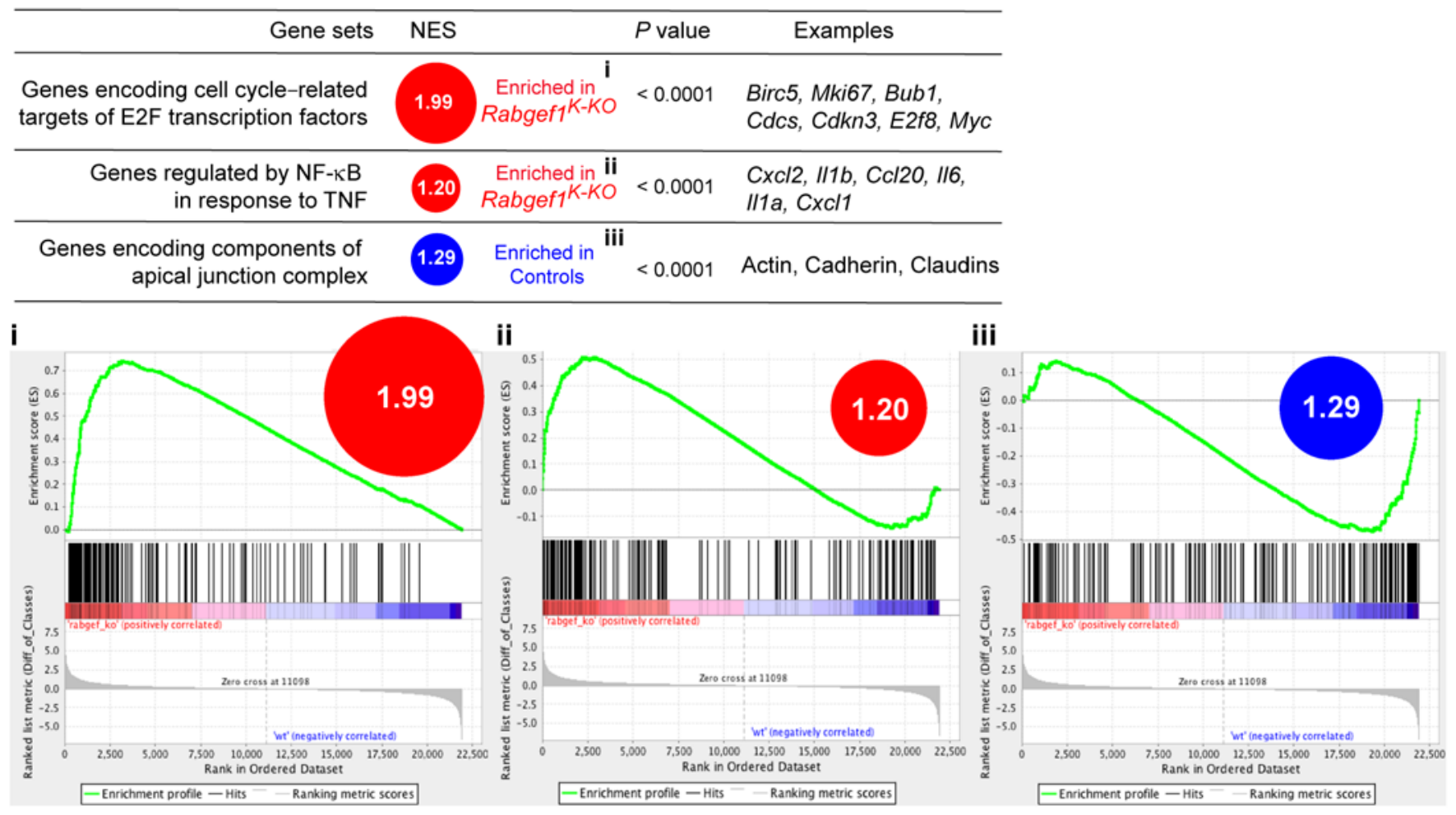

Figure 5. GSEA between Rabgef $1^{k-k o}$ and defined gene sets. Gene set enrichment analysis (GSEA) comparing the transcriptome of Rabgef ${ }^{1-k 0}$ skin with defined gene sets. Circle size is proportional to the normalized enrichment score (NES), whose numeric value is provided.

exhibited enlargement of skin-draining lymph nodes (Figure 3E) and markedly elevated concentrations of serum IgE and increased levels of IgE on blood basophils (Figure 3, F and G), as well as signs of systemic immune activation (Supplemental Figure 7). Third, quantitative reverse transcription PCR (RT-qPCR) analysis of $\mathrm{T}$ cell-associated cytokine expression in back skin from Rabgef1 ${ }^{K-K O}$ and control mice showed a significantly enhanced expression of the prototypic Th2 cytokine Il4, with smaller increases in Il17a and $I l 22$ that did not achieve statistical significance (Figure $3 \mathrm{H}$ ). Fourth, immunophenotyping of $\mathrm{CD}^{+} \mathrm{T}$ cell subsets in the ear pinnae and lymph nodes of tamoxifen-treated Rabgef $1^{\text {KERT-KO }}{ }^{-}$revealed robust increases in the numbers of GATA-3-expressing Th2 cells and Foxp3-expressing regulatory $\mathrm{T}$ cells as compared with controls, without significantly influencing the numbers of other $\mathrm{T}$ cell subsets (Figure 3, I-K).

Lack of RABGEF1 in keratinocytes results in aberrant activation of the IL-1R/MYD88/NF- $\mathrm{B}$ signaling pathway and MYD88-dependent structural abnormalities. To elucidate potential mechanisms by which keratinocyte-restricted RABGEF1 deficiency can impair epidermal barrier function and trigger type 2 inflammation, we performed a microarray analysis of back skin specimens from Rabgef $1^{K-K O}$ and control mice. Volcano plot representation of the differentially expressed genes showed 392 (Figure 4A, blue dots) and 368 (Figure 4A, red dots) upregulated genes in control and Rabgef1 ${ }^{K-K O}$ skin samples, respectively (biological fold change > 2 and adjusted $P$ value $<0.01)$. Among those genes, the expression of several genes coding for proliferation markers (e.g., Krt6a, Mki67) and innate cytokines and chemokines (e.g., Illb, Illa,
Cxcl2, Cxcl3, Ccl3) was significantly upregulated in back skin from Rabgef $1^{K-K O}$ mice versus control mice (Figure 4, B and C), suggesting that a deficiency of RABGEF1 in keratinocytes directly or indirectly influences pathways of cell proliferation and innate immunity in the skin, respectively. Supporting this, gene set enrichment analysis (GSEA), used to compare the transcriptome of Rabgef1 $1^{K-K O}$ and control skin with defined gene sets, revealed a significant enrichment, among genes upregulated in Rabgef $1^{K-K O}$ skin samples, of genes implicated in the cell cycle or regulated by NF- $\kappa \mathrm{B}$ (Figure 5). In addition, there was a significant enrichment, among genes upregulated in control skin samples, of genes involved in barrier function (Figure 5), further supporting the conclusion that epidermal barrier function is impaired when RABGEF1 is absent.

MYD88 is an adaptor molecule that plays a critical role in mediating signaling responses induced by activation of IL-1/ IL-18/Toll receptor superfamily members by coupling these receptors to the IRAK complex to induce activation of NF- $\mathrm{KB}$ and ERK-MAP kinase, leading to the release of proinflammatory cytokines $(8,37,38)$. Notably, we found a substantial increase in keratinocyte-intrinsic MYD88 protein expression in the skin of Rabgef $1^{K-K O}$ mice (Figure 4, D and E), suggesting that MYD88 may play an important role in RABGEF1-dependent signaling in keratinocytes. We used an in vitro shRNA-based approach to knock down RABGEF1 expression in a mouse keratinocyte cell line (Figure $4 \mathrm{~F}$ ) and found that such RABGEF1-deficient keratinocytes exhibited high basal levels of phosphorylation of the IKK $\alpha / \beta$ complex, I $\mathrm{B} \alpha$, and ERK-MAP kinase (Figure $4 \mathrm{G}$ ). These findings indicate that such RABGEF1-deficient keratinocytes exhibit hyperactiva- 
A
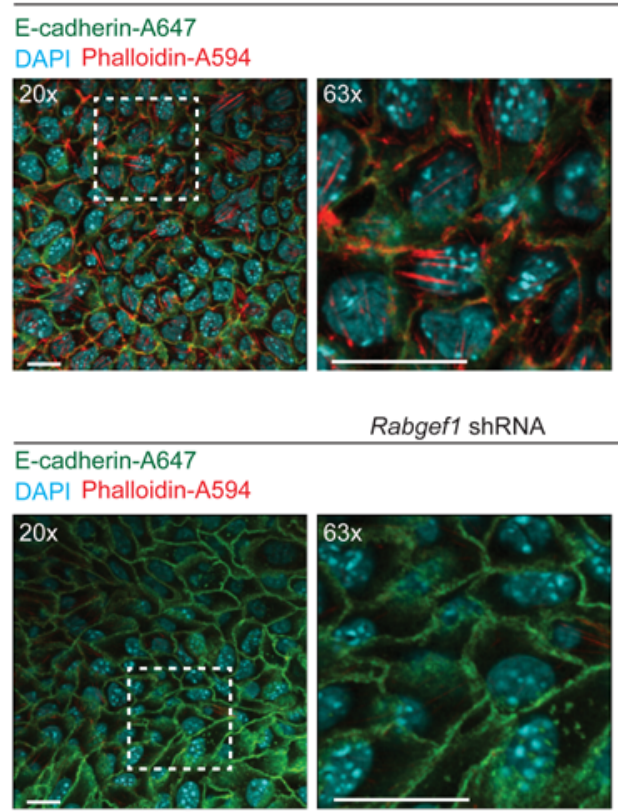

3D reconstruction

Phalloidin enrichment

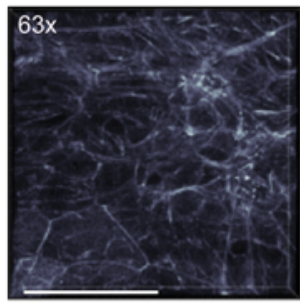

Low High

D

C

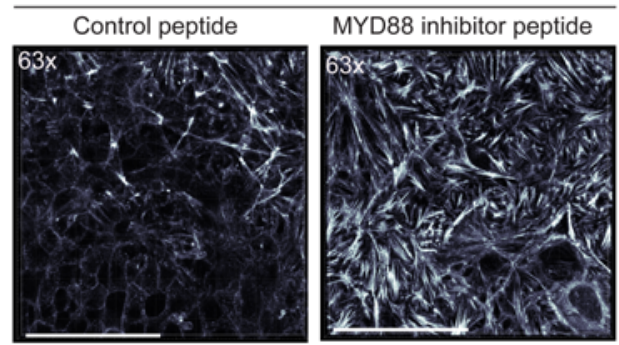

Low High
B

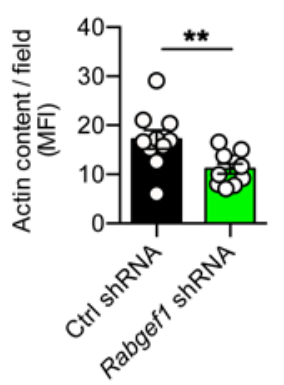

Figure 6. MYD88-dependent actin abnormalities and loss of tight junctions in RABGEF1-deficient keratinocytes. Cells from the mouse PDV keratinocyte cell line were transfected with control (Ctrl) shRNA or shRNA directed against Rabgef1 (Rabgef1 shRNA). (A)

Representative confocal microscopy pictures of phalloidin (red) and E-cadherin (green) staining merged with DAPI (cyan) and $3 \mathrm{D}$ reconstruction of phalloidin fluorescence enrichment (gray pseudocolor scale). Middle and right panels show higher-magnification photographs of the areas depicted by dashed white lines in the left panels. (B) Bars show quantification of actin content, as assessed by phalloidin staining in $\mathbf{A}$. (C) $3 D$ reconstruction of phalloidin fluorescence enrichment (gray pseudocolor scale) of Rabgef1 shRNA keratinocytes incubated for 24 hours with $100 \mu \mathrm{M}$ of MYD88 inhibitory or control peptides. (D) Bars show quantification of actin content, as assessed by phalloidin staining in $\mathbf{C}$. (E) Representative transmission electron microscopy pictures; red arrowheads indicate TJs (identified as electron-dense structures with close apposition of adjacent membranes), and blue areas are intercellular spaces. Insets depict higher-magnification photographs of the areas depicted by black squares. ( $F$ and G) Bars show quantification of the intercellular spaces (F) and TJ numbers (G).

(B, D, F, and $\mathbf{C})$ Results shown are mean \pm SEM, as well as individual values, and are pooled from 2 (B) or $3(\mathbf{D}, \mathbf{F}$, and $\mathbf{G})$ independent experiments. $P$ values were calculated using a Mann-Whitney nonparametric test. ${ }^{*} P<0.05$; ${ }^{* *} P<0.01$; ${ }^{* *} P<0.001$. Scale bars: $50 \mu \mathrm{m}$ (A and C); $250 \mathrm{~nm}$ (E); original magnification, $\times 20(\mathbf{A}$ and $\mathbf{C})$ or $\times 6,300(\mathbf{E})$.

E

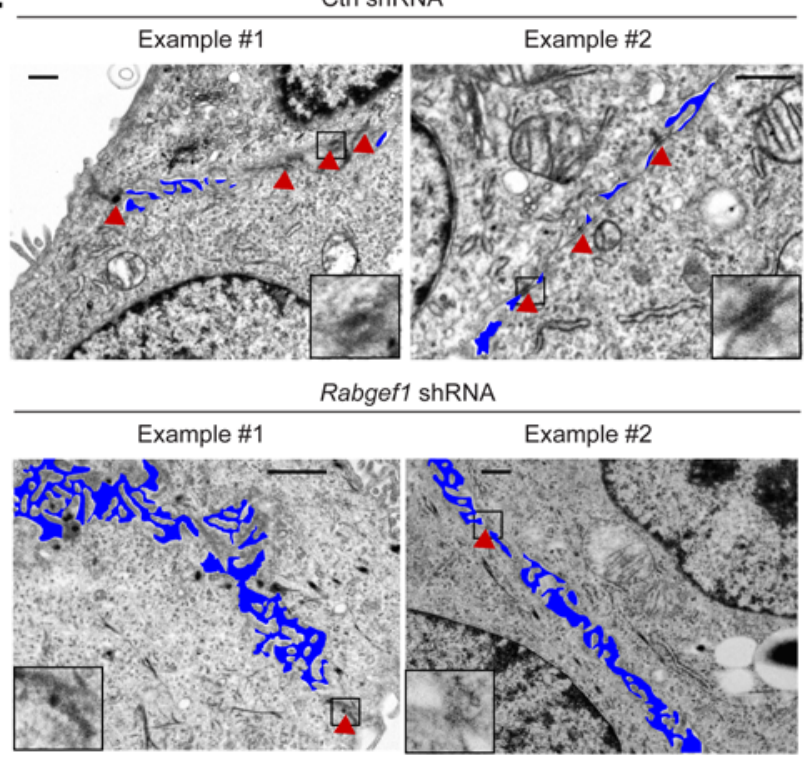

$\mathbf{F}$
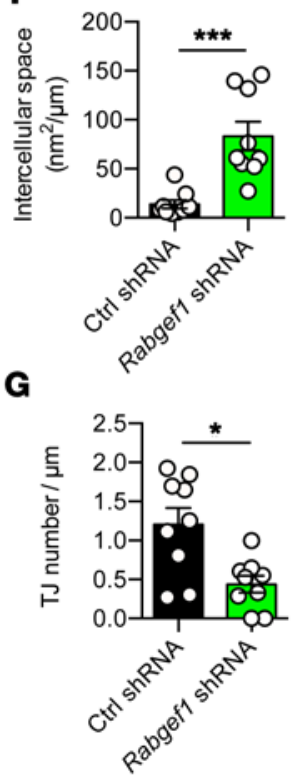
A

Rabgef1 loxP-flanked locus

Rabgef1 deleted locus
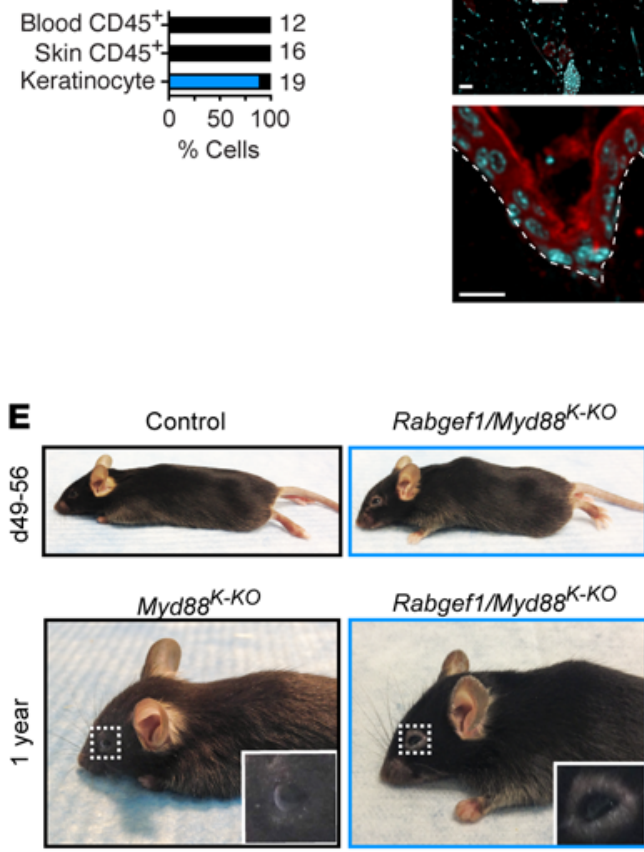

Rabgef1/Myd88 $8^{K-K O}$

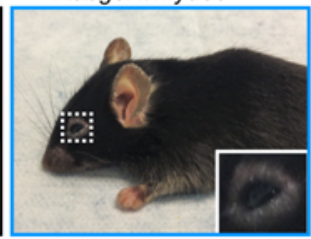

$\mathbf{H}$
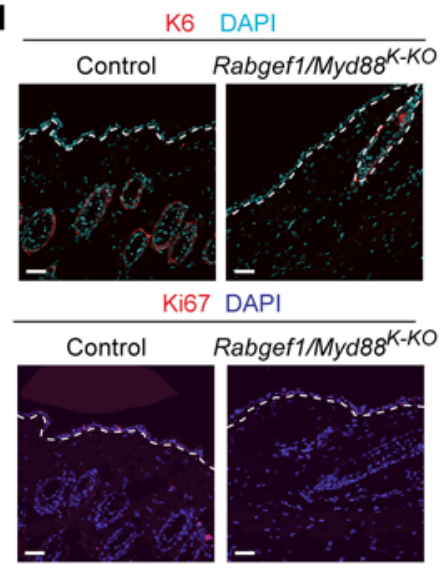

B

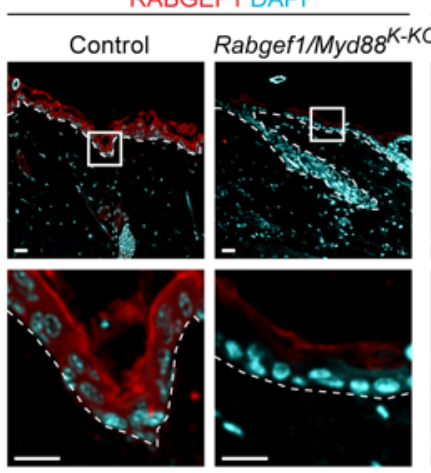

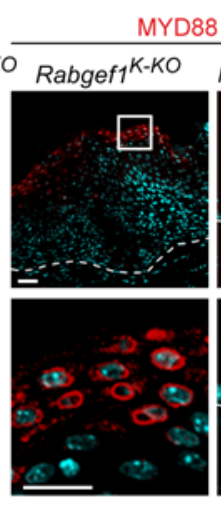

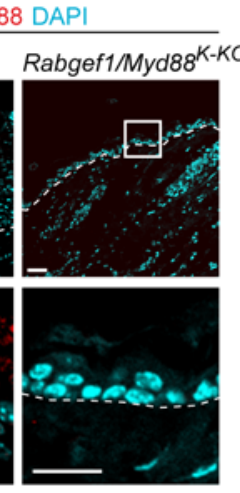

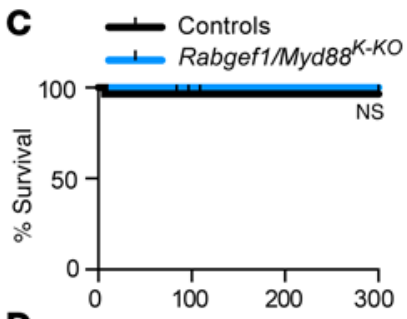

D
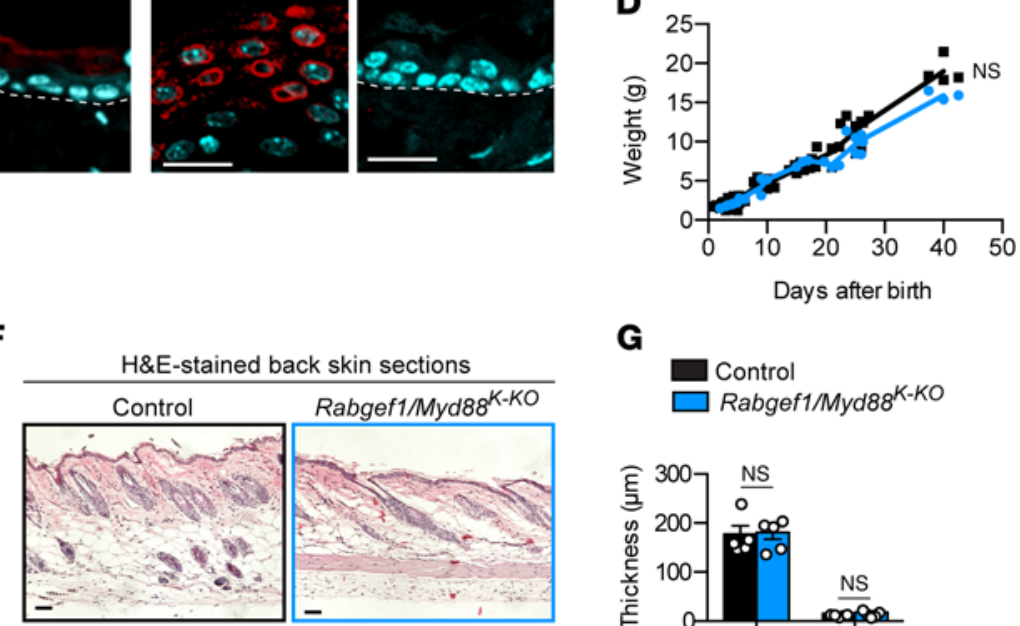

G

Control $\square$ Rabgef1/Myd88 ${ }^{K-K O}$

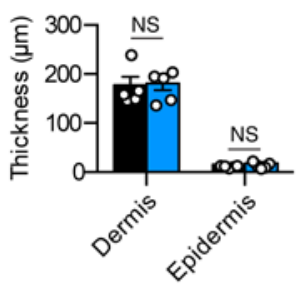

$\mathbf{K}$
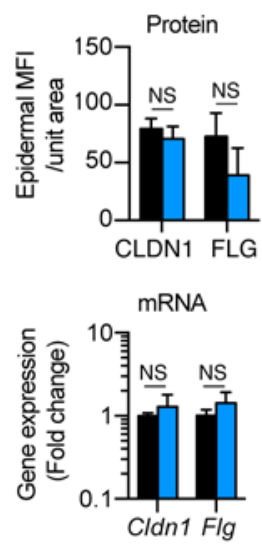

Figure 7. Critical role of keratinocyte-intrinsic MYD88 in the phenotype of Rabgef ${ }^{\text {K-Ko }}$ mice. Comparison of Rabgef1/Myd88 $8^{K-K 0}$ and control mice. (A) Specificity and efficiency of Rabgef1 gene deletion assessed by single-cell PCR; numerals indicate the number of cells analyzed for each cell type; results are pooled from 2 sorting experiments. (B) Representative RABCEF1 and MYD88 staining of back skin sections. (C and D) Survival ( $n=8-29$ mice per group) (C) and body weight ( $n=3-6$ mice per group) (D) over time. (E) Representative photographs of mice from the indicated genotype at day $49-56$ and 1 year after birth. (F) Representative H\&E staining of back skin sections. (G) Bars show quantification of dermal and epidermal thickness ( $n=5$ mice per group). ( $\mathbf{H}$ and $\mathbf{J}$ ) Representative confocal microscopy pictures of back skin sections with the indicated staining. (I and $\mathbf{K}$ ) Bars show protein and mRNA levels of the indicated molecules whose staining is depicted in $\mathbf{H}$ and $\mathbf{J}$, as assessed by confocal microscopy and RT-qPCR analyses, respectively ( $n=3-4$ per group). (B and F) Pictures are representative of 4 or 5 samples per group, each giving similar results. (B, $\mathbf{H}$, and J) Dashed lines identify the dermal-epidermal junction. $P$ values were calculated by Mantel-Cox test (C), 1-way ANOVA (D), 2-way ANOVA with Bonferroni's test for multiple comparisons (G), and 2-tailed unpaired Student's $t$ test (I and K). Scale bars: $50 \mu \mathrm{m}$; original magnification, $\times 20$ (B and I) or ×63 (J); NS, not significant.

tion of MYD88/NF- $\kappa \mathrm{B}-$ dependent signaling pathways in their basal state. Moreover, shRNA-transfected keratinocytes exhibited increased production of IL-1 $\beta$ at baseline (Figure $4 \mathrm{H}$ ), consistent with our microarray and RT-qPCR data in vivo (Figure 4, $\mathrm{B}$ and $\mathrm{C}$ ). Given that cytokines from the IL-1 family are thought to be involved in the pathogenesis of skin inflammation (24), our data support the hypothesis that in mice whose keratinocytes lack RABGEF1, activation of keratinocyte IL-1R may favor aberrant MYD88-dependent signaling and the associated development of skin barrier dysfunction and skin lesions. This idea is further 
A

Adult C57BL/6 $\| 1 r 1^{\% / \%}$ and $\| 1 r 1^{+/+}$ Rabgef 1 KERT-KO

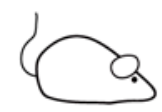

B
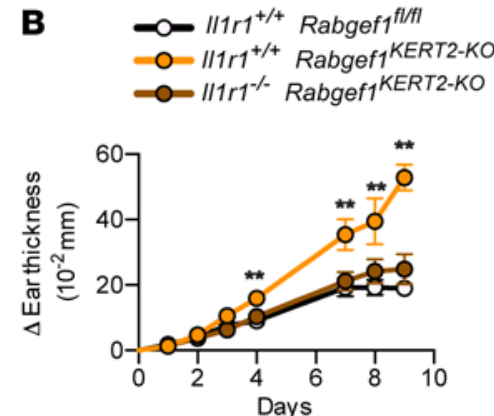

Apply tamoxifen on ear pinnae

(20 $\mu \mathrm{l}, 10 \mathrm{mg} / \mathrm{ml}$ in DMSO)
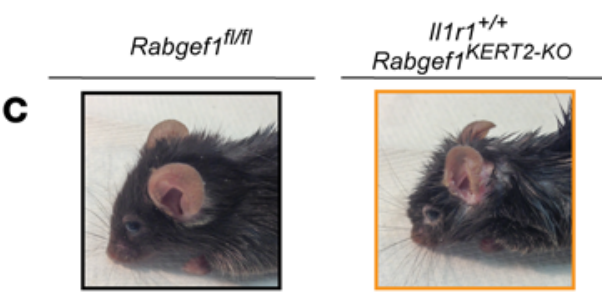

D
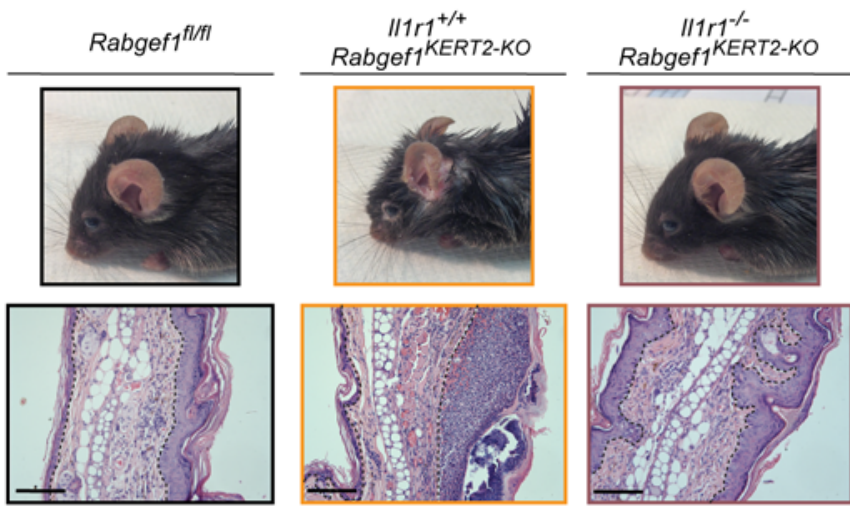

E $\| 1 / 11^{+/+}$Rabgef1 $1^{\text {flff }}$

$\square \| 111^{+/+}$Rabgef1 $1^{K E R T 2-K O}$

$\square \| 1 r^{-/}$Rabgef1 ${ }^{K E R T 2-K O}$

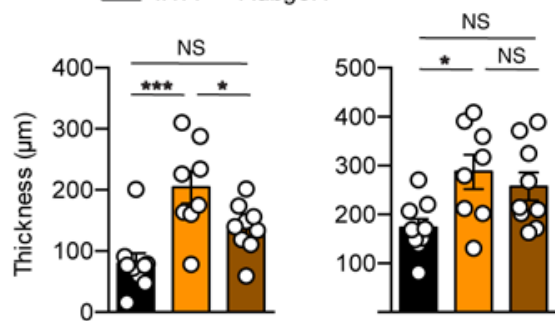

Epidermis

Dermis

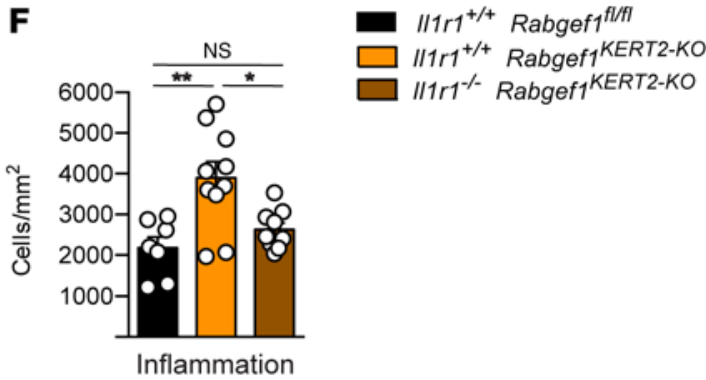

G

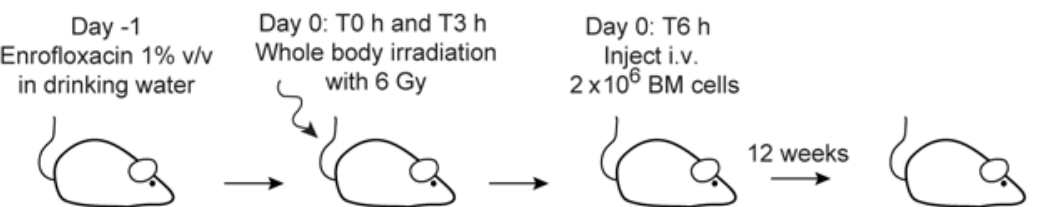

Adult C57BL/6

$111 \mathrm{r}^{-/-}$Rabgef1 KERT-KO

$\| 1 \mathrm{ri}^{+/+}$Rabgef1 ${ }^{K E R T-K O}$

BM cells from C57BL/6- $/ 11 r^{1 /-}$ mice or C57BL/6- $/ 111^{+/+}$mice

Groups:

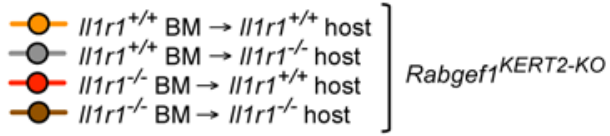

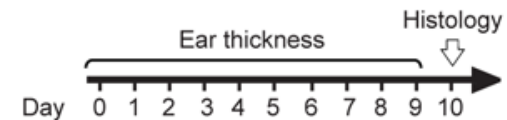

$$
\wedge \wedge \wedge \wedge \wedge A
$$

Apply tamoxifen on ear pinnae

(20 $\mu l, 10 \mathrm{mg} / \mathrm{ml}$ in DMSO)

H

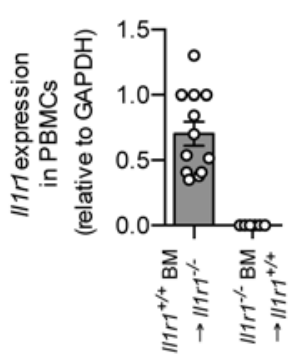

I $\| 111^{+/+}$Rabgef1 $1^{K E R T 2-K O}$

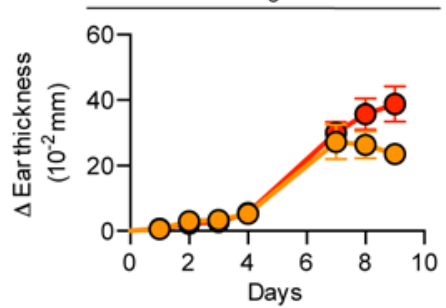

Groups:

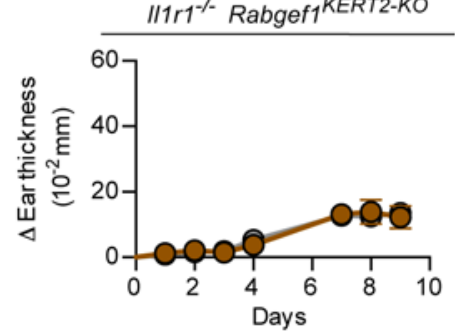

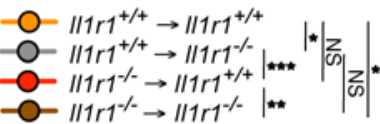

L

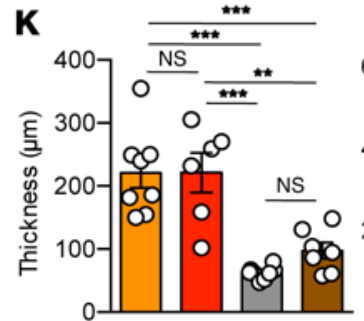

Epidermis

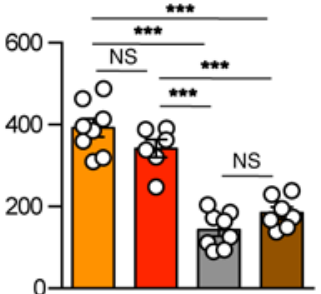

Dermis

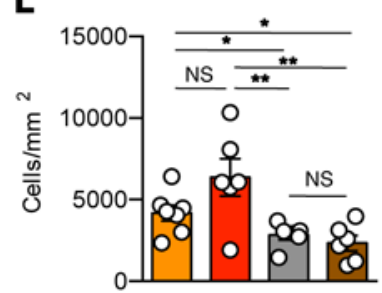

Inflammation 
Figure 8. Contribution of global and cell-specific IL-1R expression to the development of ear skin lesions in Rabgef $1^{K E R T 2-K O}$ mice following topical tamoxifen treatment. (A) Experimental outline for data shown in B-F. (B) Quantification of ear thickness over time. (C and D) Representative photographs of ear pinnae (C) and representative $\mathrm{H} \& \mathrm{E}$ staining of ear pinna sections (D). ( $\mathbf{E}$ and $\mathbf{F}$ ) Bars show quantification of epidermal and dermal thickness (E) and inflammatory cell infiltrates in the dermis (F). (G) Experimental outline for data shown in $\mathbf{H}$ and $\mathbf{~ I}$. (H) RT-qPCR analysis of I/1r1 gene expression in peripheral blood mononuclear cells (PBMCs) isolated from the indicated groups of mice. (I) Quantification of ear thickness over time. (J) Representative H\&E staining of ear pinna sections. (K and $\mathbf{L}$ ) Bars show quantification of epidermal and dermal thickness (K) and inflammatory cell infiltrates in the dermis (L). Results are shown as mean \pm SEM (as well as individual values in $\mathbf{E}, \mathbf{F}, \mathbf{H}, \mathbf{K}$, and $\mathbf{L}$ ), and are pooled from 3 independent experiments ( $n=6-12$ mice per group), each of them giving similar results. ( $\mathbf{D}$ and $\mathbf{J})$ Dashed lines identify the dermal-epidermal junction. $P$ values were calculated by 2-tailed unpaired Student's $t$ test (comparison

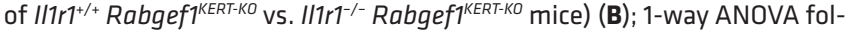
lowed by Tukey's tests for multiple comparisons (E, F, K, and L); or 2-way ANOVA followed by Sidak's tests for multiple comparisons (I). ${ }^{*} P<0.05$; ${ }^{* *} P<0.01$; ${ }^{* *} P<0.001$. Scale bars: $50 \mu \mathrm{m}$; NS, not significant.

supported by in vitro observations that shRNA-transfected RABGEF1-deficient keratinocytes exhibited enhanced levels of IкB $\alpha$ phosphorylation in response to IL-1 $\beta$ stimulation (Figure $4 \mathrm{G}$ ), indicating that the activation of MYD88-dependent signaling responses seen under basal conditions can be further enhanced in response to external stimuli. Notably, cultured RABGEF1-deficient keratinocytes did not exhibit higher rates of proliferation (data not shown), apoptosis, or necrosis (Supplemental Figure 8). Taken together, we conclude from these results that IL-1R/ MYD88/NF-kB-dependent signaling pathways are aberrantly activated in keratinocytes lacking RABGEF1.

MYD88-dependent pathways have been implicated in processes that can disrupt epithelial barrier function, via either disorganization of the actin cytoskeleton $(39,40)$ or effects on TJ function $(41,42)$. As expected, a polarized network of actin filaments was present in control keratinocytes but this network was disorganized and actin content was lower in RABGEF1-deficient keratinocytes (Figure 6, A and B). This phenotype was largely normalized by pharmacological inhibition of MYD88 in RABGEF1deficient keratinocytes, further evidence of a MYD88-dependent effect on cytoskeleton organization (Figure 6, C and D). Because optimal development of TJs is thought to depend on an organized actin network $(43,44)$, we examined the ultrastructure of intercellular junctions. The total area of intercellular space between keratinocytes was substantially larger and the number of TJs was decreased when RABGEF1 expression was reduced (Figure 6, E-G, and Supplemental Figure 9), a finding consistent with the decreased expression of the TJ protein claudin 1 in Rabgef $1^{\text {K-KO }}$ mice (see Figure 2, D and E).

These results show that RABGEF1-deficient keratinocytes exhibit cell-intrinsic MYD88-dependent defects in epidermal architecture in vitro.

Lack of keratinocyte MYD88 abrogates increased mortality, epidermal defects, and skin inflammation in Rabgef $1^{K-K O}$ mice. To assess unambiguously the role of keratinocyte-intrinsic MYD88 signaling in the phenotype of Rabgef $1^{\text {K-KO }}$ mice, we generated Rabgefl/ $M y d 88^{K-K O}$ mice, in which keratinocytes lack both MYD88 and
RABGEF1 (Figure 7, A and B). Strikingly, deletion of $M y d 88$ in RABGEF1-deficient keratinocytes largely prevented the mortality, morbidity, development of skin lesions, and epidermal hyperplasia seen in Rabgef $1^{K-K O}$ mice (Figure 7, C-G). Only some older Rabgef1/Myd88 ${ }^{K-K O}$ mice exhibited discrete areas of dry skin and periocular alopecia, while $M y d 88^{K-K O}$ mice appeared normal (Figure 7E). Moreover, analyses of Rabgef1/Myd8 $8^{K-K O}$ mice showed that MYD88 was necessary for the development of the epidermal immunohistological abnormalities (Figure 7, H and I, and Supplemental Figure 10A), increased skin cytokine expression (Supplemental Figure 10B), and defects in keratinocyte claudin 1 and filaggrin (Figure 7, J and $\mathrm{K}$ ), as well as the abnormal serum $\operatorname{IgE}$ concentrations and systemic changes observed in Rabgef ${ }^{1-K O}$ mice (Supplemental Figure 10, C-E).

$I L-1 R$ expression on radioresistant cells contributes to the skin pathology induced by keratinocyte-restricted RABGEF1 deletion. Rapidly after birth, the skin is colonized by microorganisms, which develop into a homeostatic system with the host $(45,46)$, and keratinocytes express a wide range of TLRs $(2,6,7)$, which, except for TLR-3 (9), can recognize and transduce microbe-derived signals via MYD88. Because the phenotype induced by keratinocytespecific deletion of RABGEF1 was largely restored when MYD88 was lacking, one possibility is that MYD88-mediated TLR activation by the skin microbiome contributes to the rapid development of skin lesions after birth when RABGEF1 is defective. To test this

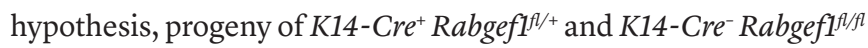
mice were rederived germ-free (GF) by embryo transfer into GF recipient mice. Of the 8 mice born in the GF environment, only 1 rapidly developed skin lesions and was significantly smaller than its littermates, and only this mouse carried the Rabgef1 ${ }^{\text {KKO }}$ genotype (data not shown). Immunohistological examination of the skin of this mouse at day 8 revealed changes like those observed in Rabgef $1^{\text {K-KO }}$ mice under conventional housing (Supplemental Figure 11). Thus, the absence of microbes did not prevent the rapid development of skin pathology in this GF-Rabgef $1^{\text {K-KO }}$ mouse, evidence that the phenotypic features of Rabgef $1^{K-K O}$ mice can develop independently of microbiome-derived signals.

We found increased Illb expression in the skin of Rabgef $1^{\text {K-KO }}$ mice (Figure 4, B and C), as well as increased IL-1 $\beta$ secretion (Figure $4 \mathrm{H}$ ) and IL-1 $\beta$-induced signaling (Figure $4 \mathrm{G}$ ) in RABGEF1-deficient keratinocytes. However, the phenotype induced by keratinocyte-specific deletion of Rabgef1 was largely restored when MYD88 also was absent in keratinocytes (Figure 7 and Supplemental Figure 10). Therefore, we speculated that activation of IL-1R may contribute to the aberrant MYD88 signaling that promotes the development of skin lesions when RABGEF1 is deficient in keratinocytes. To test this possibility, we generated Rabgef1 $1^{\text {KERT2-KO }}$ mice on the Illr1 $^{-/-}$background and evaluated the lesions induced by topical tamoxifen treatment of the ear pinnae of $I l 1 r 1^{+/+}$Rabgef $1^{\text {KERT2-KO }}$ versus $I l 1 r 1^{-/-}$Rabgef1 ${ }^{\text {KERT2-KO }}$ versus control mice (Figure $8 \mathrm{~A}$ ). While daily topical tamoxifen treatment induced ear swelling (Figure 8B) and skin lesions (Figure 8, C-F) in Il1r1 ${ }^{+/+}$Rabgef ${ }^{\text {KERT2-KO }}$ mice, all these measures were substantially decreased in tamoxifen-treated Il1r1 $1^{-/}$Rabgef1 ${ }^{\text {KERT2-KO }}$ mice (Figure 8, B-F), demonstrating that skin lesions induced by keratinocyte RABGEF1 deficiency in the ear depend on IL-1R expression. 
A
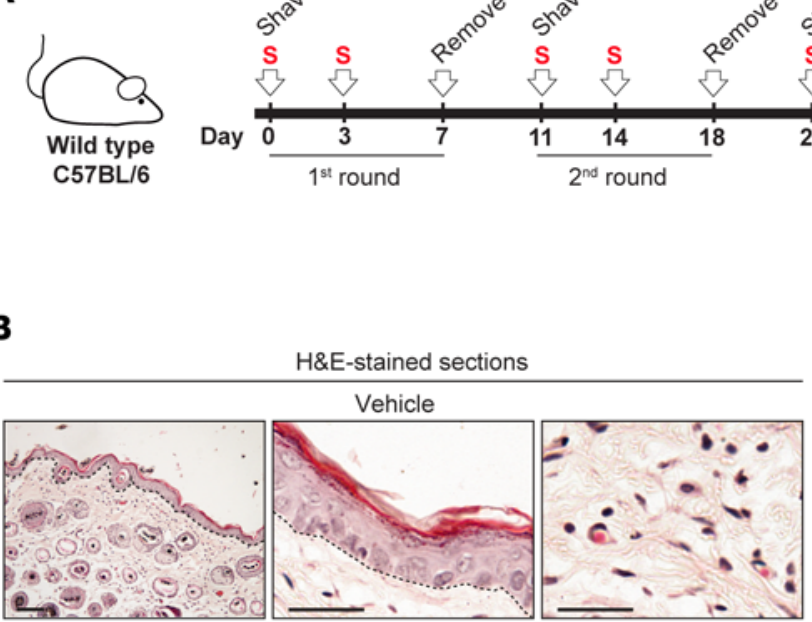

HDM/SEB
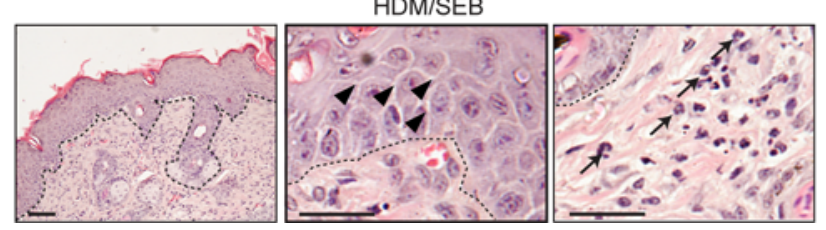

C

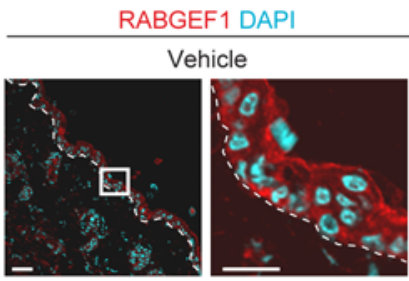

HDM/SEB

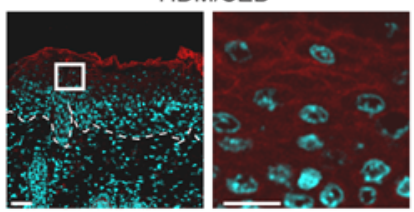

S: sensitize with $10 \mu \mathrm{g} \mathrm{HDM}+500 \mathrm{ng}$ SEB

Figure 9. RABGEF1 quantification in HDM/SEB-induced skin inflammatory lesions. (A) Experimental mouse model of HDM/SEB-induced AD used in B-D. (B) Representative H\&E staining of back skin sections from vehicle- or HDM/SEB-treated mice. Arrowheads and arrows indicate spongiosis and dermal leukocytes, respectively. (C) Representative confocal microscopy pictures of RABGEF1 staining. (D) Quantification of RABCEF1 MFI in a randomly defined region (shown in the white boxes) in back skin specimens from vehicle- or HDM/SEB-treated mice ( $n=12$ or 20 mice per group, respectively). (B and C) Dashed lines identify the dermal-epidermal junction. (D) Results are shown as mean \pm SEM. $P$ values were calculated by 2-tailed unpaired Student's $t$ test. ${ }^{* *} P<0.01$. Scale bars: $50 \mu \mathrm{m}$; original magnification in $\mathbf{C}, \times 20 ; A D$, atopic dermatitis; HDM, house dust mite; SEB, staphylococcus enterotoxin B; MFI, mean fluorescence intensity.

Next, to assess the respective contributions of IL-1R expression on myeloid versus radioresistant cells (including keratinocytes), we generated bone marrow chimeras by transferring Ill $r 1^{+/+}$or Ill $r 1^{1^{-/}}$bone marrow cells into lethally irradiated $I l 1 r 1^{+/+}$ or Il1r1 $1^{-/-}$Rabgef1 ${ }^{\text {KERT2-KO }}$ mice (Figure 8, G and H). Topical tamoxifen treatment promoted development of ear skin lesions in mice in which radioresistant cells expressed IL-1R, regardless of IL-1R expression on myeloid cells (Figure 8, I-L). The features of such lesions were significantly reduced when radioresistant cells did not express IL-1R (Figure 8, I-L). These results indicate that IL$1 \mathrm{R}$ expression on keratinocytes (and perhaps other radioresistant cells), but not on immune cells, importantly contributes to skin pathology when RABGEF1 is absent.

Keratinocyte $R A B G E F 1$ expression is diminished in a mouse model of cutaneous allergic inflammation. We next examined whether abnormalities in keratinocyte RABGEF1 expression could be observed in an inducible mouse model of skin inflammation. Specifically, we used a recently developed mouse model of AD that uses repeated epicutaneous exposures to house dust mite (HDM) extracts together with staphylococcal enterotoxin B (SEB) to induce a dermatitis associated with a global gene expression pattern comparable to that in human $\mathrm{AD}$ (refs. 47, 48, and Figure 9A). Notably, GSEA comparing this model of HDM/SEB-induced ADlike pathology with our Rabgef1 ${ }^{K-K O}$ model revealed a highly significant similarity in gene expression profiles between the 2 models (Figure 10), suggesting that skin inflammation in both models may be regulated by similar pathways. Interestingly, we found that back skin specimens from dermatitis lesions in HDM/SEB-sensitized mice exhibited a significant decrease in keratinocyte RABGEF1 expression as compared with mock-sensitized control skin (Figure 9, B-D). These observations indicate that dysregulated expression of RABGEF1 in keratinocytes can be observed in the skin lesions of experimental AD in WT mice, and may contribute to the associated skin inflammation.

Keratinocytes in human AD skin lesions exhibit decreased expression of RABGEF1, but increased expression of MYD88. To assess the human relevance of our findings, we first analyzed human normal skin specimens and skin specimens from AD and ACD patients that exhibited spongiotic dermatitis, which can be observed in either setting (refs. 49, 50, and Figure 11A). In normal human skin, RABGEF1 was mainly expressed in keratinocytes, and levels of RABGEF1 expression in keratinocytes from AD and ACD lesions were significantly lower than those in keratinocytes from normal skin (Figure 11, B and D). Moreover, levels of MYD88 were increased in keratinocytes from lesional $\mathrm{AD}$ skin as compared with normal skin (Figure 11, C and E). These observations show that keratinocytes in skin lesions of patients suffering from 2 clinically distinct allergic skin disorders exhibit markedly diminished expression of RABGEF1, while increased MYD88 expression in keratinocytes was found only in $\mathrm{AD}$ lesions.

Second, we compared our skin gene expression data from Rabgef $1^{K-K O}$ and control mice with publicly available human $\mathrm{AD}$ and normal skin data deposited in the Gene Expression Omnibus database (GSE5667, ref. 51; GSE6012, ref. 52; GSE36842, ref. 53; and 


\begin{tabular}{llll}
\multicolumn{4}{l}{ Similarity analysis of Rabgef1 ${ }^{K-K O}$ and HDM/SEB models } \\
\hline Gene sets & HDM/SEB (GSE53132) & $P$ value \\
\hline $\begin{array}{c}\text { Rabgef1 } 1^{K-K O} \\
(P<0.01, \mathrm{FC}>2)\end{array}$ & 1.29 & Enriched in HDM/SEB & $<0.0001$ \\
\hline $\begin{array}{c}\text { Control } \\
(P<0.01, \mathrm{FC}>2)\end{array}$ & $\mathbf{1 . 4 0}$ & Enriched in Controls & $<0.0001$ \\
\hline
\end{tabular}

i

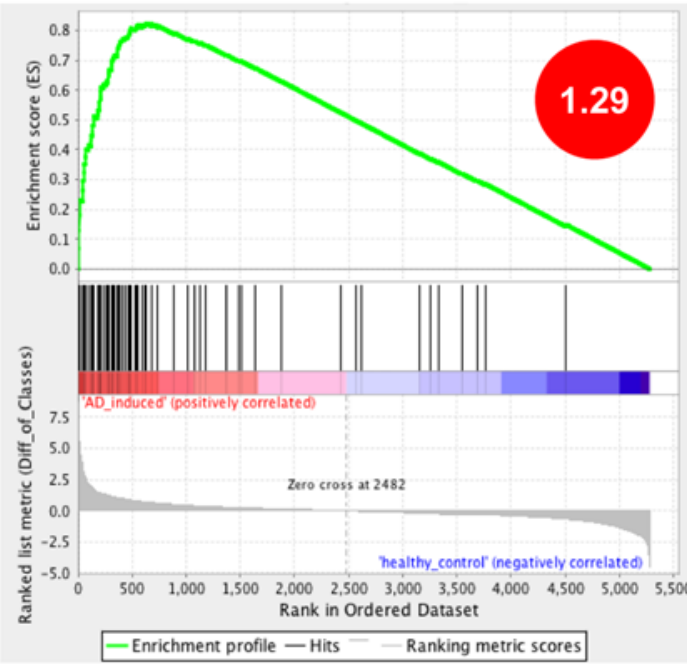

ii

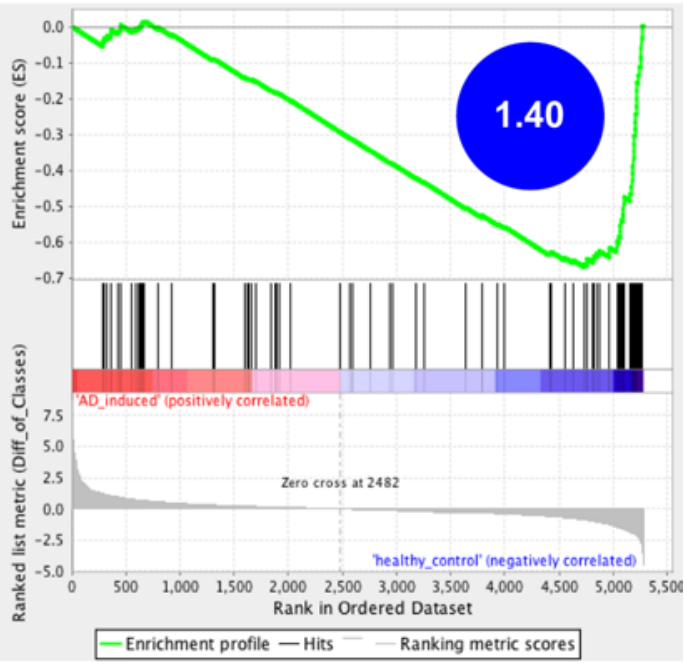

Figure 10. GSEA between Rabgef $\mathbf{T}^{\text {-ko }}$ and HDM/SEB mouse models. Gene set enrichment analysis (GSEA) comparing the HDM/SEB-induced AD model (GSE53132) with gene sets defined as upregulated genes in back skin samples from Rabgef $7^{K-K 0}$ mice or control mice $(P<0.01$; fold change [FC] $>2$; see Figure 4A). The size of the circle is proportional to the normalized enrichment score, whose numeric value is also indicated. HDM, house dust mite; SEB, staphylococcal enterotoxin B; MFI, mean fluorescence intensity.

GSE65832, ref. 54) (Figure 12). The changes in expression of genes in human $\mathrm{AD}$ versus normal skin were compared with those of orthologous genes in mouse RabGEF1 ${ }^{K-K O}$ versus control mice, and GSEA detected significant similarities in gene expression profiles between human AD skin lesions and mouse "AD-like" skin specimens, as well as between human and mouse normal skin (Figure 12).

\section{Discussion}

Our study in mice reveals that keratinocyte expression of RABGEF1 protein is critically important for the maintenance of skin homeostasis in vivo, as well as for survival. While mice with global RABGEF1 deficiency exhibited skin pathology similar to that observed in mice that lack RABGEF1 selectively in keratinocytes (31), it was not clear to what extent, if any, a lack of RABGEF1 in keratinocytes contributed to the complex constellation of cutaneous and systemic pathology that developed in Rabgef1 $1^{-/-}$mice. Indeed, given the notable importance of RABGEF1 as a negative regulator of IgE/FceRIdependent MC activation in vitro (31-33), and the finding that MCs in the skin of Rabgef1 ${ }^{--}$mice exhibited morphological evidence of degranulation in vivo (31), we initially speculated that aberrant activation of skin MCs might contribute to the skin pathology in globally RABGEF1-deficient mice. We show here that Mcpt5-Cre-mediated conditional deletion of RABGEF1 in connective tissue-type MCs did not result in impaired survival or the development of skin lesions, ruling out substantial contributions of MC-restricted RABGEF1 expression to survival or skin homeostasis.
By contrast, even though mice with $\mathrm{K} 14$-Cre-mediated keratinocyte-specific RABGEF1 deficiency (i.e., Rabgef1 ${ }^{K-K O}$ mice) appeared normal at birth, such Rabgef $1^{K-K O}$ mice spontaneously and rapidly developed severe skin lesions associated with accelerated mortality, with death occurring as early as postnatal day 5 . Microscopic analyses of the skin lesions showed marked inflammation, as well as spongiosis and hyperplasia of the epidermis associated with differentiation defects and increased proliferation of basal keratinocytes, whereas the epidermis appeared grossly and histologically normal in newborn Rabgef $1^{K-K O}$ mice. Therefore, we think it is likely that the keratinocyte defects observed in Rabgef $1^{K-K O}$ mice are a consequence of inflammation, and that RABGEF1 is not intrinsically required for keratinocyte differentiation but rather regulates another process (e.g., the activation status of keratinocytes) that is essential for skin homeostasis after birth.

Keratinocytes are crucial components of tissue homeostasis, forming a physical and immunological barrier between the environment and the host. Our data indicate that RABGEF1 deficiency in keratinocytes results in epidermal barrier dysfunction, a major factor in the pathogenesis of various inflammatory skin disorders $(1,14,15)$. Regarding skin barrier function, tamoxifen-induced epidermal RABGEF1 deficiency resulted in increased TEWL and increased uptake and endosomal digestion of OVA, delivered epicutaneously by a skin patch, by skin DCs. We also found alterations in the expression of epidermal structural proteins that contribute to barrier function, namely filaggrin and the TJ protein clau- 
A

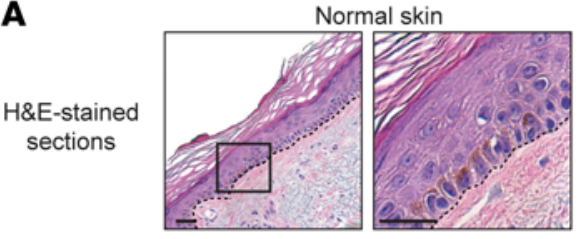

B

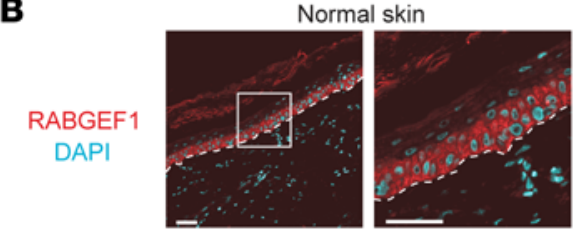

C
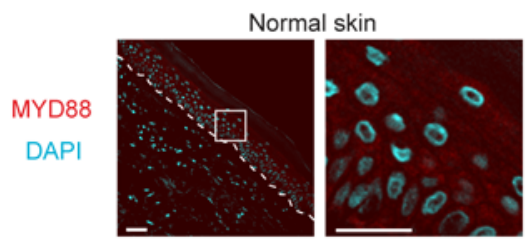

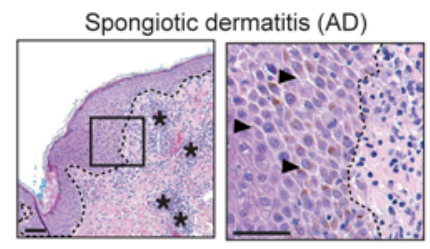

Spongiotic dermatitis (AD)

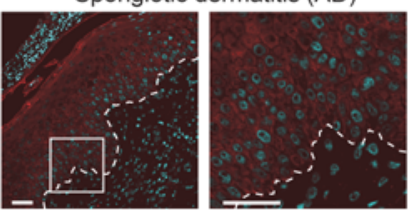

Spongiotic dermatitis (AD)
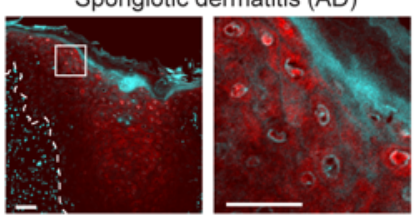

Spongiotic dermatitis (ACD)

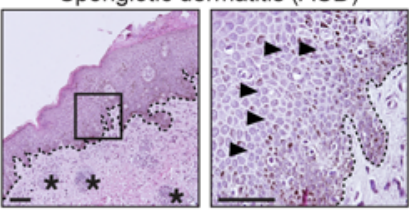

Spongiotic dermatitis (ACD)

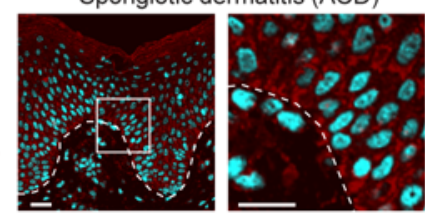

Spongiotic dermatitis (ACD)
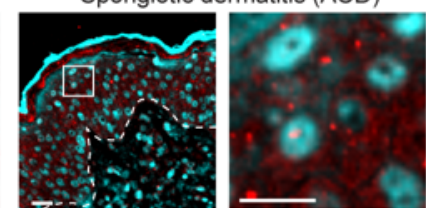

D

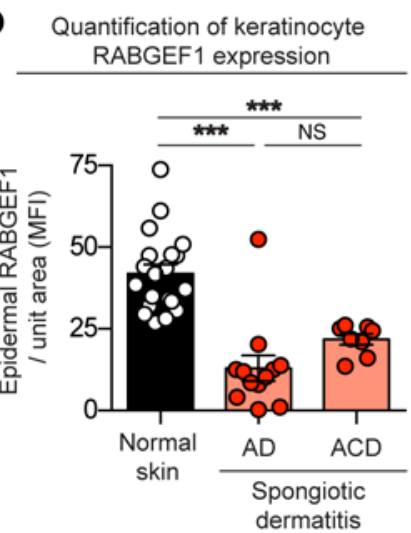

E Quantification of keratinocyte MYD88 expression

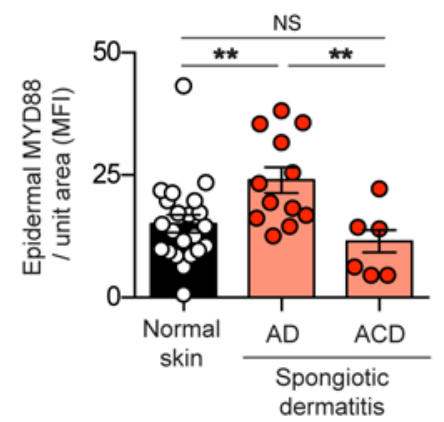

Figure 11. RABGEF1 detection and quantification in human skin lesions. (A) Representative H\&E-stained sections of normal human skin (left panels) and lesional human skin with spongiotic dermatitis from AD (middle panels) or ACD (right panels) patients; arrowheads and asterisks indicate spongiosis and dermal infiltrates of leukocytes, respectively. (B and C) Representative confocal microscopy pictures of RABCEF1 (B) or MYD88 (C) staining merged with DAPI. Right panels show higher-magnification photographs of the areas depicted by white lines in the left panels. ( $\mathbf{D}$ and $\mathbf{E}$ ) Quantification of keratinocyte RABGEF1 (D) or MYD88 (E) protein expression in a randomly defined region (shown in the boxes delimited by white dashed lines) in normal skin and lesional skin with spongiotic dermatitis from patients with AD or ACD ( $n=20,12$, and 8, respectively). See Supplemental Table 4 for patient characteristics and diagnostic criteria. (A-C) Dashed lines identify the dermal-epidermal junction. (D and E) Results are shown as mean \pm SEM, as well as individual values. $P$ values were calculated by 1 -way ANOVA followed by Tukey's tests for multiple comparisons. ${ }^{* *} P<0.01$; ${ }^{* *} P<0.001$. Scale bars: $50 \mu \mathrm{m}$; original magnification in B and C, $\times 20$; AD, atopic dermatitis; ACD, allergic contact dermatitis; NS, not significant.

din $1(4,5,19,55,56)$. The changes observed in filaggrin expression may in part reflect the decreased expression of claudin 1 , as claudin 1-deficient keratinocytes display defects in filaggrin processing (57). However, keratinocytes from filaggrin-deficient mice, unlike keratinocytes in mice selectively deficient in keratinocyte RABGEF1, display intact TJs (58). In addition to decreased expression of TJs and increased intercellular spaces in vitro, we showed that keratinocytes deficient in RABGEF1 exhibited disorganization of actin filaments. Because TJs are thought to require an organized actin network for their optimal expression $(43,44)$, it is possible that dysregulation of the intracellular actin network in keratinocytes contributes to the impairment in TJ formation, defects in filaggrin, and, ultimately, diminished barrier function that we observed in RABGEF1-deficient keratinocytes.

It has been noted that a complex crosstalk links innate signaling pathways and the expression of proteins implicated in barrier functions (59). The marked upregulation of cytokine and chemokine expression in the skin of Rabgef $1^{K-K O}$ mice prompted us to investigate whether RABGEF1 may regulate innate signaling pathways in keratinocytes. Of particular interest, MYD88-dependent responses have been shown to promote actin remodeling and downregulation of TJs (39-42), features observed in our Rabgef $1^{K-K O}$ mice. Our data show that MYD88-dependent responses in keratinocytes are enhanced in the absence of RABGEF1 and that RABGEF1-deficient keratinocytes exhibit MYD88-dependent disorganization of actin filaments in vitro and MYD88-dependent abnormalities in claudin 1 and filaggrin expression in vivo. In line with these observations, we found that MYD88 ablation in RABGEF1-deficient keratinocytes largely prevented epidermal structural defects and the development of skin lesions and also restored normal survival. These results are consistent with a scenario in which aberrant MYD88-dependent activation of RAB- 
Similarity analysis of Rabgef1 ${ }^{K-K O}$ mouse model and AD skin samples

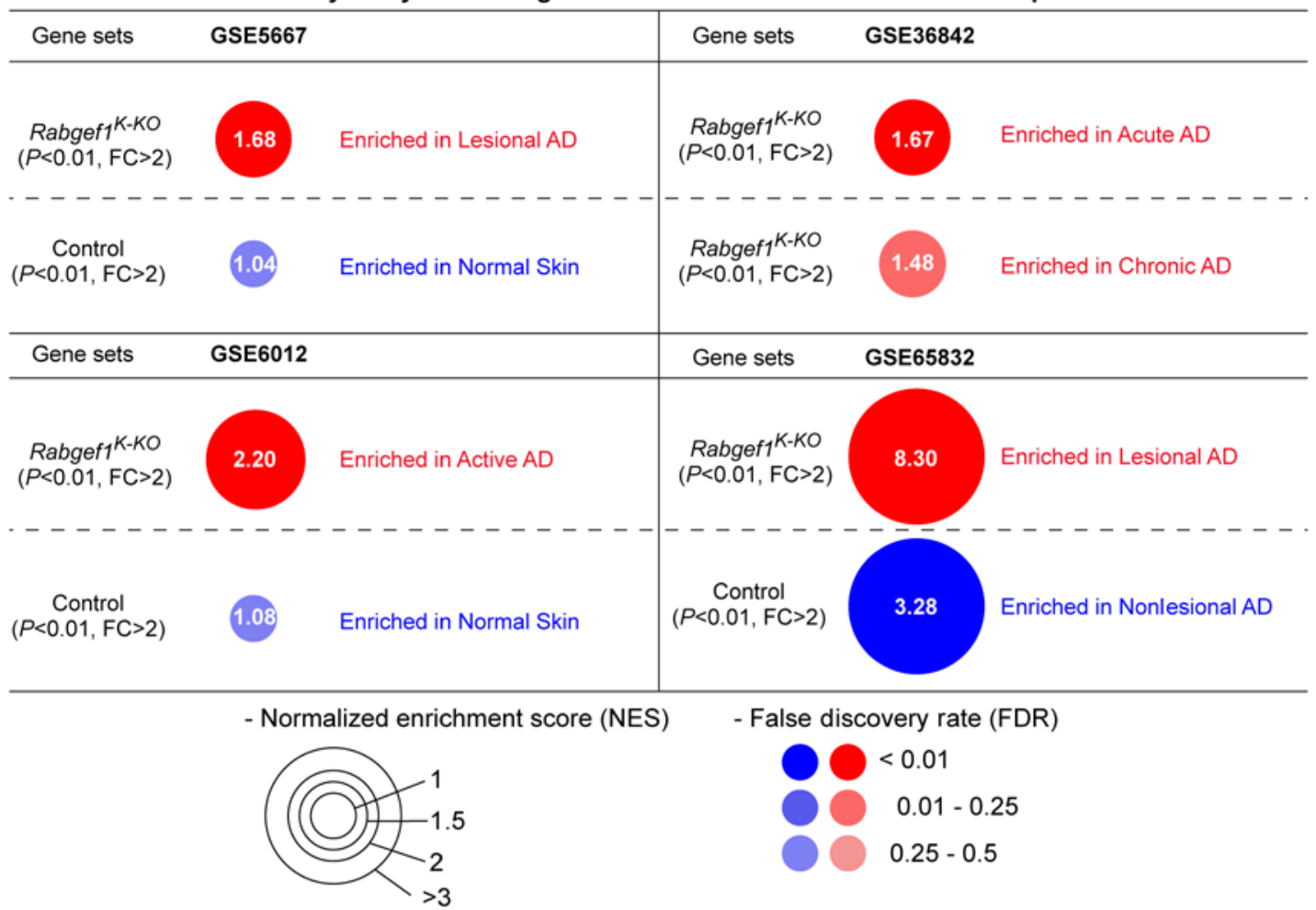

Figure 12. GSEA between Rabgef $\mathbf{1}^{\text {K-ko }}$ mouse models and AD skin samples. Gene set enrichment analysis (GSEA) comparing publicly available mRNA expression analyses of human atopic dermatitis (AD) skin lesions (also see Supplemental Table 3) with gene sets defined as upregulated genes in back skin samples from Rabgef $7^{1-k 0}$ mice or control mice $(P<0.01$; fold change $[\mathrm{FC}]>2$; see Figure $4 \mathrm{~A})$. The size of the circle is proportional to the NES, whose numeric value is also indicated.

GEF1-deficient keratinocytes results in skin barrier dysfunction via dysregulation of the intracellular actin network and impaired TJ formation. In combination with increased production of proinflammatory cytokines and chemokines, such epidermal abnormalities favor the development of type 2 skin inflammation.

Since Rabgef ${ }^{K-K O}$ mice appear normal at birth, it is likely that postnatal events initiate MYD88-dependent epidermal dysfunction in such mice. Our data show that IL-1R expression on radioresistant cells (which include keratinocytes), rather than on leukocytes, substantially contributes to skin pathology when RABGEF1 is absent in keratinocytes. Our findings also suggest that IL-1 $\beta$, which is expressed at baseline by keratinocytes and can activate IL-1R on keratinocytes, represents one important innate signal favoring the development of skin lesions in Rabgef ${ }^{1-K O}$ mice. One possibility is that, as a response to postnatal stress, keratinocytes release IL-1 $\beta$, which can aberrantly activate IL-1R and induce MYD88-dependent responses in RABGEF1-deficient keratinocytes via an autocrine mechanism. This notion is supported by reports of significant IL-1 production in normal human epidermis $(60,61)$. However, our data demonstrating a role for the IL-1R in driving the skin pathology of Rabgef $1^{K-K O}$ mice do not preclude separate or synergistic contributions of skin-colonizing microorganisms and other innate signals or cytokines in our model.

The mechanisms by which RABGEF1 regulates MYD88dependent signaling may be complex. In vitro, RABGEF1 can exhibit an E3 ubiquitin ligase activity through its A2O-like domain
$(29,32,62,63)$ and can promote GEF activity for the endocytic regulator RAB5 $(30,64)$, and both E3 ligases and endosomal trafficking have been implicated in MYD88-dependent signaling $(12,65$, 66). It therefore seems reasonable to propose that some of these functional activities may be involved in RABGEF1-mediated maintenance of skin homeostasis and homeostatic MYD88-dependent signals. Notably, mice globally deficient in A20 (67) or conditionally deficient in A2O in keratinocytes (68) exhibit a skin phenotype characterized by epidermal hyperplasia, but no skin inflammation $(67,68)$, suggesting that RABGEF1-mediated regulation of epidermal functions acts via pathways distinct from the ones targeted by the E3 ligase activity of A2O. Specifically, RABGEF1 can function as an inhibitor of NF-KB activation (69), and we have suggested that RABGEF1 might regulate NF- $\kappa$ B activation via effects on endocytosis and endosomal sorting (32). Moreover, it has been reported that overactivity of NF-kB signaling pathways can result in skin inflammation (70-72). We found that keratinocytes deficient in RABGEF1 expression exhibit intrinsic activation of NF-KB signaling pathways under basal conditions in vitro and that Rabgef $1^{\text {K-KO }}$ mice exhibit skin inflammation in vivo. These findings suggest that one important function of RABGEF1 in keratinocytes is to dampen basal levels of activation of NF- $\mathrm{KB}$ signaling (73).

Finally, we investigated whether dysregulation of epidermal RABGEF1 expression can occur in skin lesions at sites of cutaneous allergic inflammation in WT mice, as well as in humans. Using a mouse model of AD that employs environmental triggers 
thought also to contribute to human $\mathrm{AD}(47,48,74-77)$, and that shares striking similarities with our Rabgef $1^{K-K O}$ mice (see Figure 10), we showed that significant reductions in levels of RABGEF1 protein were observed by immunohistochemistry in HDM/SEBsensitized and challenged mouse skin, as compared with control skin. These findings clearly show that the induction of cutaneous allergic inflammation in WT mice is associated with significant reductions in levels of keratinocyte RABGEF1 in the induced skin lesions. In humans, we found decreased RABGEF1 protein expression and increased MYD88 protein levels in keratinocytes in AD skin lesions. A similar reduction in keratinocyte RABGEF1 expression was also observed in ACD skin lesions, but in this case, it was not accompanied by increased MYD88 expression.

In conclusion, our results in mice rendered selectively deficient in RABGEF1 in various cell types identify keratinocyte RABGEF1 as a master regulator of keratinocyte homeostasis and skin barrier function in vivo and show that a major function of keratinocyte RABGEF1 in this setting is to dampen activation of IL-1Rand MYD88-dependent pathways in epidermal keratinocytes. Our findings in humans and in a mouse model of cutaneous allergic inflammation indicate that reduced expression of RABGEF1 also can occur in keratinocytes at the sites of skin lesions in subjects who presumably lack genetic abnormalities in Rabgef1. The latter observations raise the possibility that changes in levels of keratinocyte RABGEF1 may importantly contribute to the pathology of skin disorders associated with aberrations of skin barrier function.

\section{Methods}

Mice. Six- to 8-week-old female C57BL/6J mice were used in experiments involving solely WT mice. Rabgefl floxed (Rabgef $1^{f / f f}$ ) mice were first generated on the C57BL/6N background by insertion of 2 loxP sites on both sides of Rabgef 1 exon 2 and further crossed to C57BL/6J Flp-deleter mice to remove the Neo cassette (inGenious Targeting

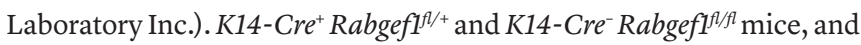

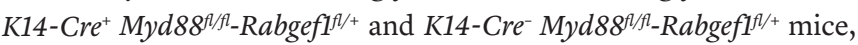
were used as breeders for the generation of Rabgef $1^{K-K O}$ and Rabgefl/ $M y d 88^{K-K O}$ mice, respectively, and littermates were used as controls in all experiments. Transgenic R26R-eYFP, lysozyme Z-Cre (Lysz-Cre), K14-Cre, $\mathrm{Myd} 88^{f / f l}$, and $I l 1 r 1^{-/-}$mice were from The Jackson Laboratory. Mcpt5-Cre (78) and Kert-2R-Cre (79) mice have been described previously. Mice were bred and housed in the local animal facilities, and littermate control mice were used in all experiments. Seven- to 9-week-old Kert-2R-Cre $\mathrm{Rabgef1}^{\mathrm{ft} / \mathrm{fl}}$ and control mice (i.e., Kert-2R-CreRabgef $\left.\mathrm{f}^{f / f t}\right)$ were used in experiments involving tamoxifen-induced Rabgef1 deletion. Germ-free (GF) Rabgef $1^{K-K O}$ and control mice were rederived at Taconic and maintained in sterile isolators in gnotobiotic animal facilities (laboratory of Justin Sonnenburg, Stanford University Medical Center, Stanford, California, USA). GF status was monitored following rederivation at Taconic and monthly at Stanford by anaerobic and aerobic culture of cecal contents.

Reagents and antibodies. BSA, saponin, sodium citrate, tamoxifen, DMSO, staphylococcal enterotoxin B (SEB), dispase, and corn oil were from Sigma-Aldrich. Mouse recombinant IL-1 $\beta$ was purchased from R\&D Systems. A MYD88 inhibitory peptide (i.e., a cell-permeant peptide sequence that selectively blocks MYD88 homodimerization) (80) and a control peptide (i.e., an inactive and cell-permeant truncated form of the MYD88 inhibitory peptide) were from Novus. Derma- tophagoides farinae extracts (house dust mite, HDM) were purchased from Greer Laboratories. Additional details on antibodies and other reagents used in this study can be found in the Supplemental Methods.

Preparation of cell suspensions and flow cytometry. Skin cell suspensions were prepared as described previously (81). Briefly, samples of skin tissue were cut into small pieces and digested for 1 hour at $37^{\circ} \mathrm{C}$ in HBSS containing $20 \mathrm{mM}$ HEPES, $0.025 \mathrm{mg} / \mathrm{ml}$ Liberase TM, and $396 \mathrm{U} / \mathrm{ml}$ DNase I (Roche). Cell suspensions from the esophagus, stomach, duodenum, jejunum, colon, and lung were obtained following enzymatic digestion for 1 hour at $37^{\circ} \mathrm{C}$ in HBSS containing $1 \mathrm{mg} /$ $\mathrm{ml}$ collagenase A (Roche) and $0.05 \mathrm{mg} / \mathrm{ml}$ DNase I (Roche). Lymph nodes and spleens were minced and cells were recovered using a $70-\mu \mathrm{m}$ cell strainer. Spleen and white blood cells were obtained following 2 rounds of red blood cell lysis using ACK (ammonium-chloridepotassium) lysing buffer. Peritoneal lavages were performed with $4 \mathrm{ml}$ PBS. Cells were incubated with $2.4 \mathrm{G} 2 \mathrm{Fc}$ receptor blocking antibodies before staining and were kept at $4^{\circ} \mathrm{C}$ during processing. Aqua-Amine (Life Technologies) was used to eliminate dead cells. Cells were analyzed with a FACS LSR-II and were sorted (for single-cell sorting) into 96-well plates with a BD Influx/Carmen cytometer. Results were analyzed using FlowJo software (Tree Star).

Single-cell sorting and PCRs. Single-cell sorting, phenotypes of sorted cell populations, and single-cell PCRs are described in the Supplemental Methods.

Skin section preparation, histology, and quantification of epidermal/ dermal thickness and inflammation. Mouse back skin $\left(1 \mathrm{~cm}^{2}\right)$ samples, ear pinnae, and other organs were fixed in $10 \%$ formalin and were embedded in paraffin. Four-micrometer-thick sections were stained with $\mathrm{H} \& \mathrm{E}$, and photographs were taken using a Nikon E1000M microscope and analyzed with Spot 5.1 Advanced Software. For immunostaining of mouse specimens, $4-\mu \mathrm{m}$-thick sections were pretreated using a heat-induced epitope retrieval method (82) in $10 \mathrm{mM}$ sodium citrate buffer ( $\mathrm{pH}$ 6.0), then permeabilized for 30 minutes in PBS supplemented with $0.5 \%$ BSA and $0.1 \%$ saponin. Sections were "coded" so the evaluator was not aware of their identity. Additional details regarding quantification of epidermal/dermal thickness and inflammation can be found in the Supplemental Methods.

Immunostaining and confocal microscopy. Permeabilized skin sections were incubated overnight at $4^{\circ} \mathrm{C}$ with primary antibodies, extensively washed, and incubated with appropriate secondary antibodies and/or Alexa Fluor 488-conjugated avidin for 2 hours at room temperature in the dark (see Supplemental Table 1 for the references and dilutions of antibodies used). Additional details regarding preparation and confocal analyses of keratinocytes in vitro, image acquisition, processing, and quantification can be found in the Supplemental Methods.

Experiments involving tamoxifen-inducible Rabgef1 deletion. For assessment of RABGEF1 protein deletion, TEWL measurements, and OVA-DQ uptake experiments, Rabgef1 ${ }^{\text {KERT2-KO }}$ and Rabgeff ${ }^{f / f l}$ control mice were shaved on the back the day before the beginning of treatment (day 0). From day 1 to day $5,40 \mu \mathrm{l}$ tamoxifen $(10 \mathrm{mg} / \mathrm{ml}$ in DMSO) or DMSO was applied daily, topically on the shaved skin. At day 4, TEWL was measured using a Tewameter TM 300 (Courage + Khazaka electronic $\mathrm{GmbH}$ ), and results were analyzed using MPACK software. Eight days after the start of treatment with tamoxifen or vehicle, mice were patched with OVA-DQ (Life Technologies) for 30 hours to assess OVA uptake and processing, with a protocol adapted from Geha and collaborators (83), but without tape stripping. OVA- 
DQ is a quenched, nonfluorescent protein that becomes fluorescent green when processed in acidic endosomes and also fluorescent red when it accumulates at high concentrations in these compartments. $\mathrm{CD} 45^{+} \mathrm{CD} 11 \mathrm{c}^{\text {hi }} \mathrm{MHC}-\mathrm{II}{ }^{\text {hi }}$ dermal DCs were analyzed by flow cytometry for their fluorescence intensity in green and red channels. At day 10, the mice were euthanized and back skin specimens were obtained for (immuno)histological analyses.

For quantification of $\mathrm{T}$ cell subsets and ear skin lesion development, $20 \mu$ tamoxifen $(10 \mathrm{mg} / \mathrm{ml}$ in corn oil) was applied daily from day 0 to day 5 , topically on the ear pinnae. At day 10 , the mice were euthanized and ear pinna specimens were collected for analyses. In some experiments (Figure 8), ear pinna thickness was measured daily with a dial thickness gauge (G-1A; Ozaki). For quantification of T cell subsets, ear pinnae were separated into 2 parts along the cartilage and maintained overnight at $4^{\circ} \mathrm{C}$ in a dispase solution $(2 \mathrm{U} / \mathrm{ml})$. The dermis was separated from the epidermis and then was enzymatically digested ( 1 hour at $37^{\circ} \mathrm{C}$ in HBSS containing $1 \mathrm{mg} / \mathrm{ml}$ collagenase A and $0.05 \mathrm{mg} / \mathrm{ml}$ DNase I), and single-cell suspensions were obtained. Cells were stained according to the protocol of the Transcription Factor Buffer Set kit (BD Biosciences).

In vitro keratinocyte culture and shRNA-mediated RABGEF1 knockdown. PDV mouse keratinocytes (84) were cultured in complete DMEM according to the manufacturer's protocol (CLS). Details regarding shRNA-mediated RABGEF1 knockdown and stimulation experiments can be found in the Supplemental Methods.

$R N A$ isolation and $m R N A$ expression analyses. Back skin samples (1 $\mathrm{cm}^{2}$ ) were collected from the same anatomical location in 7-week-old female Rabgef $1^{K-K O}$ and control mice (at the center of the back, behind the shoulders). Tissue RNA was isolated using Trizol (Life Technologies) and transcribed into cDNA using the High Capacity cDNA Reverse Transcription Kit (Applied Biosystems).

Gene expression analysis was performed using microarrays (Affymetrix Mouse Genome 4302.0 array), and microarray data were analyzed using Bioconductor for R (85). Microarray data have been deposited in the ArrayExpress public database, accession number E-MTAB-5000 (http://www.ebi.ac.uk/arrayexpress/experiments/ E-MTAB-5000).

Additional details can be found in the Supplemental Methods.

For real-time PCRs, target gene Ct levels (primer sequences available in Supplemental Table 2) were normalized to the housekeeping gene Eef1b2 in the same sample. Relative gene expression compared with that in healthy controls was calculated using the $2^{\Delta \Delta \mathrm{Ct}}$ algorithm.

Gene set enrichment analysis. Methodological details of GSEA can be found in the Supplemental Methods.

Measurement of serum IgE. Concentrations of total serum IgE were quantified by ELISA, as described previously (86).

Immunoblotting. Experimental details can be found in the Supplemental Methods. The full, uncut gels used to make Figure 4, F and G, are shown in Supplemental Figure 12.

Transmission electron microscopy. Experimental details can be found in the Supplemental Methods.

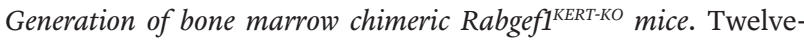

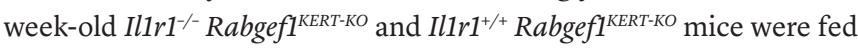
autoclaved water with enrofloxacin ( $1 \% \mathrm{vol} / \mathrm{vol})$ and were lethally irradiated 24 hours later with 2 doses of 6 Gy 3 hours apart. Three hours after the second irradiation, mice were injected i.v. with $2 \times 10^{6}$ bone marrow cells isolated from the femurs and tibias of $I l 1 r 1^{-/-}$or $I l 1 r 1^{+/+}$
C57BL/6 mice. Twelve weeks later, Il1r1 mRNA expression was determined in peripheral blood mononuclear cells by RT-qPCR, and Rabgef1 gene deletion was induced as described above.

Mouse model of HDM/SEB-induced AD. Dermatitis was induced in C57BL/6 mice as previously described (refs. 47, 48, and Figure 9A). See the Supplemental Methods for additional information.

Statistics. Statistical tests were performed using the software GraphPad Prism 5.0. Mantel-Cox test, 1-way or 2-way ANOVA, and Mann-Whitney or unpaired 2-tailed Student's $t$ test were performed as mentioned in the respective figure legends. A $P$ value less than 0.05 was considered significant $\left({ }^{*} P<0.05 ;{ }^{* *} P<0.01 ;{ }^{* * *} P<0.001,{ }^{* * *} P<0.0001\right)$.

Study approval. All small-laboratory-animal care and experiments were carried out in accord with current $\mathrm{NIH}$ guidelines and with the approval of the Institutional Animal Care and Use Committee at Stanford University (reference 29402) or the University of Liège (reference 1535).

For immunohistological studies of human skin, normal skin specimens and lesional skin specimens exhibiting spongiotic dermatitis that were obtained for diagnostic purposes from patients with a history and clinical findings of AD or ACD (Supplemental Table 4) were provided by the tissue bank of the Department of Pathology at Stanford Hospital. The use of these specimens was approved by the Institutional Review Board of Stanford Hospital. Samples were anonymized before the histological analysis.

\section{Author contributions}

SJG, MT, SYT, and TM conceived the project. TM, NG, SE, PS, LLR, FB, YK, TK, SYT, MT, and SJG were involved in experimental design. TM and NG performed most of the experiments, analyzed and compiled the data, and contributed equally to this work. RS, OZ, PS, SE, LLR, NA, and SYT helped with experiments. DP performed the bioinformatics analyses. JK helped to analyze the skin histopathology. PC and AA provided mice. NA was involved in transmission electron microscopy experiments. SYT performed Western blot analyses. FB and SJG secured funding. All authors participated in writing or editing the paper.

\section{Acknowledgments}

We thank all members of the Galli laboratory for discussions, Chen Liu, Mariola Liebersbach, Steven Higginbottom, Cedric François, and Joëlle Piret for technical assistance, and Justin L. Sonnenburg for advice regarding studies with germ-free mice. TM was supported by a Marie Curie International Outgoing Fellowship for Career Development: European Union's Seventh Framework Programme (FP7-PEOPLE-2011-IOF), 299954, and a "Chargé de recherches" fellowship of the Belgian National Fund for Scientific Research (F.R.S.-FNRS). TM is currently a Research Associate of the F.R.S.-FNRS and is supported by the Acteria Foundation. NG was supported by fellowships from the French Fondation pour la Recherche Médicale (FRM; award SPE20130326582) and the Philippe Foundation. PS was supported by a Max Kade Fellowship of the Max Kade Foundation and the Austrian Academy of Sciences and a Schroedinger Fellowship of the Austrian Science Fund (FWF) (J3399-B21). LLR was supported by the Arthritis National Research Foundation and NIH grant K99AI110645. This work was supported by grants from the F.R.S.-FNRS (to FB), by NIH grants AIO23990, CA072074, AI070813, and AR067145 (to SJG), and by the Department of Pathology, Stanford University School of Medicine. 
Address correspondence to: Stephen J. Galli, Department of Pathology, Stanford University School of Medicine, Center for Clinical Sciences Research, 269 Campus Drive, Room 3255b, Stanford, California 94305-5176, USA. Phone: 650.736.6014; E-mail: sgalli@ stanford.edu. Or to: Mindy Tsai, Department of Pathology, Stanford University School of Medicine, Center for Clinical Sciences Research, 269 Campus Drive, Room 3255a, Stanford, California 94305-5176, USA.Phone:650.736.0071;E-mail:mindyt@stanford. edu. Or to: See-Ying Tam, Department of Pathology, Stanford University School of Medicine, Center for Clinical Sciences Research, 269 Campus Drive, Room 3255c, Stanford, California 94305-5176, USA. Phone: 650.736.0061; E-mail: stam@stanford.edu.

PS's present address is: CeMM Research Center for Molecular Medicine of the Austrian Academy of Sciences, and Department of Medicine I, Medical University of Vienna, Vienna, Austria.
1. Kubo A, Nagao K, Amagai M. Epidermal barrier dysfunction and cutaneous sensitization in atopic diseases. J Clin Invest. 2012;122(2):440-447.

2. Kuo IH, Yoshida T, De Benedetto A, Beck LA. The cutaneous innate immune response in patients with atopic dermatitis. JAllergy Clin Immunol. 2013;131(2):266-278.

3. Irvine AD, McLean WH, Leung DY. Filaggrin mutations associated with skin and allergic diseases. N Engl JMed. 2011;365(14):1315-1327.

4. Furuse M, et al. Claudin-based tight junctions are crucial for the mammalian epidermal barrier: a lesson from claudin-1-deficient mice. JCell Biol. 2002;156(6):1099-1111

5. Kirschner N, Brandner JM. Barriers and more: functions of tight junction proteins in the skin. Ann N Y Acad Sci. 2012;1257:158-166

6. Miller LS. Toll-like receptors in skin. Adv Dermatol. 2008;24:71-87.

7. Terhorst D, Kalali BN, Ollert M, Ring J, Mempel $\mathrm{M}$. The role of toll-like receptors in host defenses and their relevance to dermatologic diseases. Am J Clin Dermatol. 2010;11(1):1-10.

8. O'Neill LA, Bowie AG. The family of five: TIRdomain-containing adaptors in Toll-like receptor signalling. Nat Rev Immunol. 2007;7(5):353-364.

9. Kawai T, Akira S. The role of pattern-recognition receptors in innate immunity: update on Toll-like receptors. Nat Immunol. 2010;11(5):373-384.

10. Swamy M, Jamora C, Havran W, Hayday A. Epithelial decision makers: in search of the 'epimmunome'. Nat Immunol. 2010;11(8):656-665.

11. Pasparakis M. Regulation of tissue homeostasis by NF-kappaB signalling: implications for inflammatory diseases. Nat Rev Immunol. 2009;9(11):778-788.

12. Kondo T, Kawai T, Akira S. Dissecting negative regulation of Toll-like receptor signaling. Trends Immunol. 2012;33(9):449-458.

13. Flohr C, Mann J. New insights into the epidemiology of childhood atopic dermatitis. Allergy. 2014;69(1):3-16.

14. Holgate ST. The epithelium takes centre stage in asthma and atopic dermatitis. Trends Immunol. 2007;28(6):248-251.

15. Cookson W. The immunogenetics of asthma and eczema: a new focus on the epithelium. Nat Rev Immunol. 2004;4(12):978-988.

16. Kaplan DH, Igyártó BZ, Gaspari AA. Early immune events in the induction of allergic contact dermatitis. Nat Rev Immunol. 2012;12(2):114-124

17. Novak N, et al. Loss-of-function mutations in the filaggrin gene and allergic contact sensitization to nickel. J Invest Dermatol. 2008;128(6):1430-1435.

18. Palmer $\mathrm{CN}$, et al. Common loss-of-function vari- ants of the epidermal barrier protein filaggrin are a major predisposing factor for atopic dermatitis. Nat Genet. 2006;38(4):441-446.

19. Kawasaki H, et al. Altered stratum corneum barrier and enhanced percutaneous immune responses in filaggrin-null mice. J Allergy Clin Immunol. 2012;129(6):1538-1546.e6.

20. Scharschmidt TC, et al. Filaggrin deficiency confers a paracellular barrier abnormality that reduces inflammatory thresholds to irritants and haptens. J Allergy Clin Immunol. 2009;124(3):496-506, 506.e1

21. Yoo J, et al. Spontaneous atopic dermatitis in mice expressing an inducible thymic stromal lymphopoietin transgene specifically in the skin. JExp Med. 2005;202(4):541-549.

22. Jariwala SP, Abrams E, Benson A, Fodeman J, Zheng $\mathrm{T}$. The role of thymic stromal lymphopoietin in the immunopathogenesis of atopic dermatitis. Clin Exp Allergy. 2011;41(11):1515-1520.

23. Liu YJ, et al. TSLP: an epithelial cell cytokine that regulates $\mathrm{T}$ cell differentiation by conditioning dendritic cell maturation. Annu Rev Immunol. 2007;25:193-219.

24. Abramovits W, Rivas Bejarano JJ, Valdecantos WC. Role of interleukin 1 in atopic dermatitis. Dermatol Clin. 2013;31(3):437-444.

25. Corsini E, Galli CL. Epidermal cytokines in experimental contact dermatitis. Toxicology. 2000;142(3):203-211.

26. Oyoshi MK, He R, Kumar L, Yoon J, Geha RS. Cellular and molecular mechanisms in atopic dermatitis. Adv Immunol. 2009;102:135-226.

27. Leung DY, Bieber T. Atopic dermatitis. Lancet. 2003;361(9352):151-160.

28. Novak N. New insights into the mechanism and management of allergic diseases: atopic dermatitis. Allergy. 2009;64(2):265-275.

29. Penengo L, et al. Crystal structure of the ubiquitin binding domains of rabex- 5 reveals two modes of interaction with ubiquitin. Cell. 2006;124(6):1183-1195.

30. Delprato A, Merithew E, Lambright DG. Structure, exchange determinants, and family-wide rab specificity of the tandem helical bundle and Vps9 domains of Rabex-5. Cell. 2004;118(5):607-617.

31. Tam SY, et al. RabGEF1 is a negative regulator of mast cell activation and skin inflammation. Nat Immunol. 2004;5(8):844-852.

32. Kalesnikoff J, et al. Roles of RabGEF1/Rabex-5 domains in regulating Fc epsilon RI surface expression and Fc epsilon RI-dependent responses in mast cells. Blood. 2007;109(12):5308-5317.

33. Kalesnikoff J, et al. RabGEF1 regulates stem cell factor/c-Kit-mediated signaling events and biological responses in mast cells. Proc Natl Acad Sci US A. 2006;103(8):2659-2664
34. Tsai M, et al. Thymic stromal lymphopoietin contributes to myeloid hyperplasia and increased immunoglobulins, but not epidermal hyperplasia, in RabGEF1-deficient mice. Am J Pathol. 2010;177(5):2411-2420.

35. Weiss RA, Eichner R, Sun TT. Monoclonal antibody analysis of keratin expression in epidermal diseases: a 48- and 56-kdalton keratin as molecular markers for hyperproliferative keratinocytes. J Cell Biol. 1984;98(4):1397-1406.

36. Fluhr JW, Feingold KR, Elias PM. Transepidermal water loss reflects permeability barrier status: validation in human and rodent in vivo and ex vivo models. Exp Dermatol. 2006;15(7):483-492.

37. Warner N, Núñez G. MyD88: a critical adaptor protein in innate immunity signal transduction. Jimmunol. 2013;190(1):3-4.

38. Wesche H, Henzel WJ, Shillinglaw W, Li S, Cao Z. MyD88: an adapter that recruits IRAK to the IL-1 receptor complex. Immunity. 1997;7(6):837-847.

39. West MA, et al. Enhanced dendritic cell antigen capture via toll-like receptor-induced actin remodeling. Science. 2004;305(5687):1153-1157.

40. West MA, et al. TLR ligand-induced podosome disassembly in dendritic cells is ADAM17 dependent. J Cell Biol. 2008;182(5):993-1005.

41. Clarke TB, Francella N, Huegel A, Weiser JN. Invasive bacterial pathogens exploit TLR-mediated downregulation of tight junction components to facilitate translocation across the epithelium. Cell Host Microbe. 2011;9(5):404-414.

42. Guo S, Al-Sadi R, Said HM, Ma TY. Lipopolysaccharide causes an increase in intestinal tight junction permeability in vitro and in vivo by inducing enterocyte membrane expression and localization of TLR-4 and CD14. Am J Pathol. 2013;182(2):375-387.

43. Vaezi A, Bauer C, Vasioukhin V, Fuchs E. Actin cable dynamics and Rho/Rock orchestrate a polarized cytoskeletal architecture in the early steps of assembling a stratified epithelium. Dev Cell. 2002;3(3):367-381.

44. Nusrat A, et al. Rho protein regulates tight junctions and perijunctional actin organization in polarized epithelia. Proc Natl Acad Sci US A. 1995;92(23):10629-10633.

45. Nakatsuji T, Chiang HI, Jiang SB, Nagarajan H, Zengler K, Gallo RL. The microbiome extends to subepidermal compartments of normal skin. Nat Commun. 2013;4:1431.

46. Zeeuwen PL, Kleerebezem M, Timmerman HM, Schalkwijk J. Microbiome and skin diseases. Curr Opin Allergy Clin Immunol. 2013;13(5):514-520.

47. Ando T, et al. Mast cells are required for full expression of allergen/SEB-induced skin inflammation. J Invest Dermatol. 2013;133(12):2695-2705.

48. Kawakami Y, Yumoto K, Kawakami T. An 
improved mouse model of atopic dermatitis and suppression of skin lesions by an inhibitor of Tec family kinases. Allergol Int. 2007;56(4):403-409.

49. Ming ME. Book and new media reviews: An atlas of histopathology of skin diseases: An illustrated textbook and reference for clinicians. Arch Dermatol. 2000;136(7):944.

50. Trautmann A, Akdis M, Bröcker EB, Blaser K, Akdis CA. New insights into the role of T cells in atopic dermatitis and allergic contact dermatitis. Trends Immunol. 2001;22(10):530-532.

51. Plager DA, et al. Early cutaneous gene transcription changes in adult atopic dermatitis and potential clinical implications. Exp Dermatol. 2007;16(1):28-36.

52. Olsson $\mathrm{M}$, et al. Increased expression of aquaporin 3 in atopic eczema. Allergy. 2006;61(9):1132-1137.

53. Gittler JK, et al. Progressive activation of $\mathrm{T}(\mathrm{H}) 2 / \mathrm{T}(\mathrm{H}) 22$ cytokines and selective epidermal proteins characterizes acute and chronic atopic dermatitis. J Allergy Clin Immunol. 2012;130(6):1344-1354.

54. Suárez-Fariñas M, et al. RNA sequencing atopic dermatitis transcriptome profiling provides insights into novel disease mechanisms with potential therapeutic implications. J Allergy Clin Immunol. 2015;135(5):1218-1227.

55. O'Regan GM, Irvine AD. The role of filaggrin lossof-function mutations in atopic dermatitis. Curr Opin Allergy Clin Immunol. 2008;8(5):406-410.

56. De Benedetto A, et al. Tight junction defects in patients with atopic dermatitis. JAllergy Clin Immunol. 2011;127(3):773-86.e1.

57. Sugawara T, et al. Tight junction dysfunction in the stratum granulosum leads to aberrant stratum corneum barrier function in claudin-1-deficient mice. J Dermatol Sci. 2013;70(1):12-18.

58. Yokouchi M, et al. Epidermal tight junction barrier function is altered by skin inflammation, but not by filaggrin-deficient stratum corneum. J Dermatol Sci. 2015;77(1):28-36.

59. González-Mariscal L, Tapia R, Chamorro D. Crosstalk of tight junction components with signaling pathways. Biochim Biophys Acta. 2008;1778(3):729-756.

60. Gahring LC, Buckley A, Daynes RA. Presence of epidermal-derived thymocyte activating factor/ interleukin 1 in normal human stratum corneum.
J Clin Invest. 1985;76(4):1585-1591.

61. Hauser C, Saurat JH, Schmitt A, Jaunin F, Dayer JM. Interleukin 1 is present in normal human epidermis. J Immunol. 1986;136(9):3317-3323.

62. Lee $S$, et al. Structural basis for ubiquitin recognition and autoubiquitination by Rabex- 5 . Nat Struct Mol Biol. 2006;13(3):264-271.

63. Mattera R, Tsai YC, Weissman AM, Bonifacino JS. The Rab5 guanine nucleotide exchange factor Rabex- 5 binds ubiquitin (Ub) and functions as a Ub ligase through an atypical Ub-interacting motif and a zinc finger domain.J Biol Chem. 2006;281(10):6874-6883.

64. Horiuchi H, et al. A novel Rab5 GDP/GTP exchange factor complexed to Rabaptin-5 links nucleotide exchange to effector recruitment and function. Cell.1997;90(6):1149-1159.

65. Chuang TH, Ulevitch RJ. Triad3A, an E3 ubiquitin-protein ligase regulating Toll-like receptors. Nat Immunol. 2004;5(5):495-502.

66. Husebye H, et al. Endocytic pathways regulate Tolllike receptor 4 signaling and link innate and adaptive immunity. EMBO J. 2006;25(4):683-692.

67. Lee EG, et al. Failure to regulate TNF-induced $\mathrm{NF}-\mathrm{kB}$ and cell death responses in A20-deficient mice. Science. 2000;289(5488):2350-2354.

68. Lippens S, et al. Keratinocyte-specific ablation of the NF- $\mathrm{KB}$ regulatory protein A20 (TNFAIP3) reveals a role in the control of epidermal homeostasis. Cell Death Differ. 2011;18(12):1845-1853.

69. Diatchenko L, et al. Identification of novel mediators of NF- $\mathrm{kB}$ through genome-wide survey of monocyte adherence-induced genes. J Leukoc Biol. 2005;78(6):1366-1377.

70. Lippens S, Hoste E, Vandenabeele P, Agostinis $\mathrm{P}$, Declercq W. Cell death in the skin. Apoptosis. 2009;14(4):549-569.

71. Pasparakis M, Luedde T, Schmidt-Supprian M. Dissection of the NF- $\mathrm{\kappa B}$ signalling cascade in transgenic and knockout mice. Cell Death Differ. 2006;13(5):861-872.

72. Seitz CS, Freiberg RA, Hinata K, Khavari PA. NF- $\mathrm{KB}$ determines localization and features of cell death in epidermis. JClin Invest. 2000;105(3):253-260.

73. Rebholz B, et al. Crosstalk between keratinocytes and adaptive immune cells in an I $\mathrm{B} \alpha$ proteinmediated inflammatory disease of the skin.
Immunity. 2007;27(2):296-307.

74. Kobayashi T, et al. Dysbiosis and Staphylococcus aureus colonization drives inflammation in atopic dermatitis. Immunity. 2015;42(4):756-766.

75. Leung DY, et al. Presence of IgE antibodies to staphylococcal exotoxins on the skin of patients with atopic dermatitis. Evidence for a new group of allergens. J Clin Invest. 1993;92(3):1374-1380.

76. Leyden JJ, Marples RR, Kligman AM. Staphylococcus aureus in the lesions of atopic dermatitis. Br J Dermatol. 1974;90(5):525-530.

77. Nakamura Y, et al. Staphylococcus $\delta$-toxin induces allergic skin disease by activating mast cells. Nature. 2013;503(7476):397-401.

78. Scholten J, et al. Mast cell-specific Cre/loxPmediated recombination in vivo. Transgenic Res. 2008;17(2):307-315.

79. Li M, et al. Skin abnormalities generated by temporally controlled RXR $\alpha$ mutations in mouse epidermis. Nature. 2000;407(6804):633-636

80. Benedetti F, et al. Sulfur compounds block MCP-1 production by Mycoplasma fermentans-infected macrophages through NF-kB inhibition. J Transl Med. 2014;12:145.

81. Dudeck A, et al. Mast cells are key promoters of contact allergy that mediate the adjuvant effects of haptens. Immunity. 2011;34(6):973-984.

82. Gaudenzio N, Laurent C, Valitutti S, Espinosa E. Human mast cells drive memory $\mathrm{CD} 4{ }^{+} \mathrm{T}$ cells toward an inflammatory IL-22+ phenotype. J Allergy Clin Immunol. 2013;131(5):1400-7.e11.

83. He R, Oyoshi MK, Wang JY, Hodge MR, Jin H, Geha RS. The prostaglandin $\mathrm{D}_{2}$ receptor CRTH2 is important for allergic skin inflammation after epicutaneous antigen challenge. J Allergy Clin Immunol. 2010;126(4):784-790.

84. Caulín C, Scholl FG, Frontelo P, Gamallo C, Quintanilla M. Chronic exposure of cultured transformed mouse epidermal cells to transforming growth factor- $\beta 1$ induces an epithelial-mesenchymal transdifferentiation and a spindle tumoral phenotype. Cell Growth Differ. 1995;6(8):1027-1035.

85. Gentleman RC, et al. Bioconductor: open software development for computational biology and bioinformatics. Genome Biol. 2004;5(10):R80.

86. Marichal T, et al. A beneficial role for immunoglobulin $\mathrm{E}$ in host defense against honeybee venom. Immunity. 2013;39(5):963-975. 